\title{
Voltage-Based Control of a Smart Transformer in a Microgrid
}

\author{
T. L. Vandoorn, J. D. M. De Kooning, B. Meersman, J. M. Guerrero and L. Vandevelde
}

\begin{abstract}
For the islanded operation of a microgrid, several control strategies have been developed. For example, voltage-based droop control can be implemented for the active power control of the generators and the control of the active loads. One of the main advantages of a microgrid is that it can be implemented as a controllable entity within the electrical network. This requires the ability of the utility grid to control or influence the power exchange with the microgrid by communicating with only one unit. However, little research has been conducted on controlling the power transfer through the point of common coupling. This paper addresses this issue by introducing the concept of a smart transformer (ST) at the point of common coupling. This unit controls the active power exchange between a microgrid and the utility grid dependent on the state of both networks and other information communicated to the ST. To control the active power, the ST uses its taps that change the microgrid-side voltage at the PCC. This voltage-based control of the ST is compatible with the voltage-based droop control of the units in the microgrid that is used in this paper. Hence, the microgrid units can automatically respond to changes of ST set points and vice versa. Several simulation cases are included in this paper to demonstrate the feasibility of the ST concept.
\end{abstract}

Index Terms-Islanded microgrid, voltage-source inverter, active power control, droop control, active load control, point of common coupling

\section{INTRODUCTION}

In the electrical distribution system, a steadily increasing number of distributed generation (DG) units with renewable or non-renewable energy sources for local power generation has been obtained over the last years. The shift towards nearload generation can make the grid more reliable and increase the efficiency, if the network: 1) is properly coordinated and operated, 2) effectively faces the challenges posed by the integration of renewable energy sources. In this context, the microgrid concept has been developed [1]-[3], a schematic overview of which is given in Fig. 11 The microgrid facilitates the penetration of DG units into the utility grid as it delivers a coordinated way for their integration by dealing with the unconventional behavior of DG [3]. Microgrids offer significant benefits in both the grid perspective and the consumer

Manuscript received April 1, 2011. Accepted for publication August 8, 2011 Copyright (c) 2009 IEEE. Personal use of this material is permitted. However, permission to use this material for any other purposes must be obtained from the IEEE by sending a request to pubs-permissions@ieee.org.

T. L. Vandoorn, J. D. M. De Kooning, B. Meersman and L. Vandevelde are with the Electrical Energy Laboratory (EELAB), Department of Electrical Energy, Systems and Automation (EESA), Ghent University, SintPietersnieuwstraat 41, B-9000 Ghent, Belgium, Phone: +32 926434 22, e-mail: Tine.Vandoorn@UGent.be

J. M. Guerrero is with the Dept. of Automatic Control Systems and Computer Engineering, Technical University of Catalonia, 08036 Barcelona, Spain \& Dept. Energy Technology, Aalborg University, Pontoppidanstraede 101/45, 9220 Aalborg East, Denmark

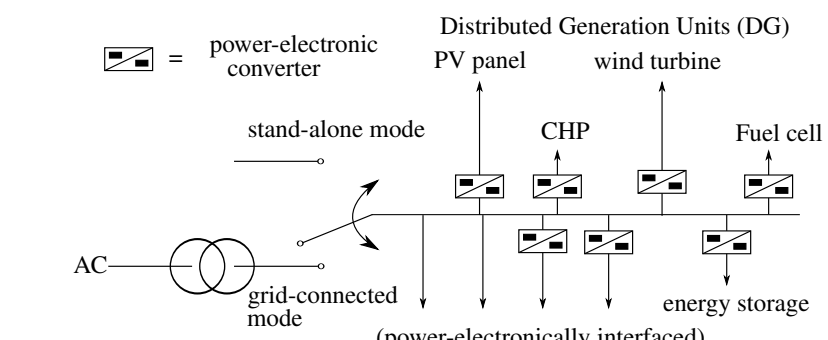

Utility grid transformer PCC $\begin{array}{r}\text { (power-electronically } \\ \text { distributed loads }\end{array}$

Fig. 1. Microgrid with (power-electronically interfaced) loads, storage and DG units in stand-alone or grid-connected mode

perspective [4]-[7]. A key advantage from the grid point of view is that the whole microgrid appears to the power network as a single controllable unit [8]. From the customers point of view, the impact of the microgrid on the reliability of the distribution network is relevant, certainly in the future, with more unpredictable generation and higher consumption (peaks). Another new concept besides the microgrid, is the smart grid that drives the electrical grid to become smarter and more flexible in the future. Microgrids are likely to play a key role in the evolution of the smart grid [9], as microgrids are better positioned than the centralized electrical network to meet the needs of the future and stimulate innovations. In this sense, the smart grid can emerge as a system of integrated smart microgrids [10], leading to an increasing interest in intelligent microgrids [11]. The microgrid can be considered and exploited as the main building block of the smart grid [12]. Microgrids and smart grids are being tested and demonstrated in many projects such as the E.U. Microgrid Projects, the U.S. Certs Microgrid, BC Hydro in Canada, the NEDO microgrid projects in Japan and the European SmartGrids Technology Platform [2], [13]-[18].

In terms of active power control, the DG units can be categorized in dispatchable and undispatchable units. The power of the dispatchable DG units can be changed by the power control strategy, often by implementing a droop control method [19]-[26]. In contrast, the output power of undispatchable DG units such as photovoltaic panels and wind turbines, is normally controlled based on an optimal operating condition of an energy source [23].

As the interfaces between the DG units and the microgrid are often based on power-electronic converters [27], microgrid control requires implementing a proper control strategy in these converters [28]. In the grid-connected mode of the microgrid, the DG units deliver power to both local loads and the utility grid. The reference voltage is then taken from the grid voltage. In the islanded mode on the other hand, the DG units determine their own voltage to share the total load demand. In this paper, 
a grid voltage/dc-link voltage droop controller is used. This controller is combined with active power/grid voltage droop control. The latter controller has an operation dependent on the grid voltage level in order to fully exploit the advantages of both dispatchable and undispatchable units and to avoid voltage limit violation [29].

The integration of large amounts of (renewable-based) DG units poses some challenges in the electrical network. The current practice is to decide for each DG unit whether or not to allow it in a specific place. However, this does not lead to an optimized amount of DG. The microgrid concept promises to address this issue by enabling microgrids to become controllable entities within the electrical network [2], [8], [12]. Then, the power exchange between the microgrid and the utility network needs to be controlled. One solution for this is that the utility network communicates new set points to all (or specified) DG units and active loads, e.g., by using the multi-agent strategy of [30]. However, this does not comply with the droop control strategy that avoids inter-unit communication to operate in a distributed manner. A possibility is, thus, that the utility network only needs to communicate to the point of common coupling (PCC), and the microgrid droop controllers automatically respond.

Little research has been conducted on the power transfer through the PCC, much research concerning microgrids deals with either grid-connected or islanded operation or the transition between both [31]-[35]. Therefore, in this paper, this power exchange is controlled by means of a tap-changing transformer located at the PCC, called the smart transformer (ST). The main aspects of the ST are: 1) the ST controls the bidirectional power transfer between utility grid and microgrid, 2) the ST is able to aggregate information to determine its set point of power exchange, 3) the ST enables to exploit the microgrid as a controllable entity, because the utility network only needs to communicate to the ST instead of all microgrid elements.

To control the power exchange between the main grid and the microgrid, the ST changes the microgrid-side voltage. Therefore, the voltage-based droop control of the generators and active loads is combined with a voltage-based control of the ST. In this way, firstly, the microgrid can automatically, without need for communication, adapt to changes of the ST power, and vice versa. Secondly, the ST makes it possible to keep the same control methods for the DG units and active loads in both islanded mode and grid-connected mode.

In this context, the usage of the ST can be implemented as a level between the primary control and the secondary control. For the actual secondary control, one possibility is to use a central controller with low-bandwidth communication with each DG unit to change their set points in order to minimize a potential function [12] or using a communicationbased hierarchical control [36].

The remainder of this paper is divided into five sections. First, an overview of the used voltage-based active power and active load control strategies in an islanded microgrid is given. Second, the concept of the ST is introduced. In the third paragraph, a proof of concept for the ST located at the PCC in a simple microgrid is shown, proving that the ST enables control of the power exchange to the microgrid. Next, a ST is implemented in a microgrid. Finally, a microgrid with ST subjected to dynamic changes is studied. The simulations show a proper operation of the ST. They also illustrate that the ST enables to exploit the microgrid as a controllable entity that automatically adjusts to changes of the ST voltage.

In order to introduce the concept of the smart transformer, first, the active power control strategy of the generators and active loads in [29], [37] are summarized. Further in this paper, the smart transformer (ST) will follow an analogous control strategy to control the power exchange between microgrid and utility network. Because of this analogous control, the microgrid can adapt to changes of the ST without communication.

\section{A. Active power control of the generators}

\section{Concept}

The active power controller of the DG units defines the reference terminal voltage $v_{\mathrm{g} \text {,ref }}(t)$ of their voltage-source inverter (VSI) interface, which is depicted in Fig. 2. Because of the mainly resistive nature of the low-voltage microgrid lines, a linkage between active power $P$ and rms voltage $V_{\mathrm{g}}$, and, a linkage between reactive power $Q$ and phase angle differences are valid [38]. Therefore, $P / V_{\mathrm{g}}$ droops and $Q / f$ droops [39] are used to determine $v_{\mathrm{g}, \mathrm{ref}}(t)$. In Fig. 3, a general overview is given of the controllers, the details are discussed further in this paper.

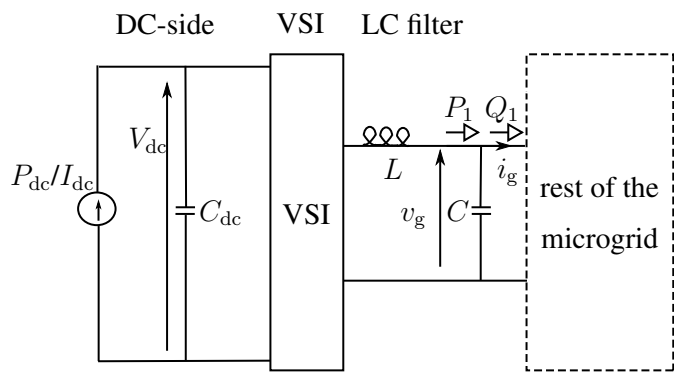

Fig. 2. VSI-interface of the DG units

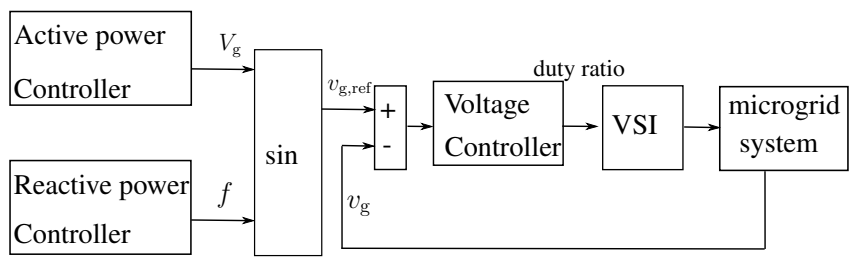

Fig. 3. Outer power control loop and inner voltage control loop

The active power controller of the generators, namely the voltage-based droop controller, is based on two control strategies [29], with their operation dependent on the microgrid rms voltage. In a voltage band around the nominal microgrid voltage, which is called the constant-power band, only the $V_{\mathrm{g}} / V_{\mathrm{dc}}$ droop control strategy is active. If the dc-link voltage $V_{\mathrm{dc}}$ of a DG unit increases, which indicates that the ac-side power $P$ is less than the dc-side power $P_{\mathrm{dc}}$, this unit will increase its terminal grid voltage $V_{\mathrm{g}}$ according to:

$$
V_{\mathrm{g}}=V_{\mathrm{g}, \mathrm{nom}}+a\left(V_{\mathrm{dc}}-V_{\mathrm{dc}, \mathrm{nom}}\right),
$$


where 'nom' denotes nominal values. Even a slight change of $V_{\mathrm{g}}$ leads to a change of the power delivered to the electrical network. This effect is realised by a natural balancing due to the loads (such as loads with demand response as in $\S$ I-C or resistive loads) and the microgrid lines. This first controller keeps the generated power constant.

If the microgrid voltage exceeds this constant-power band, also a $P_{\mathrm{dc}} / V_{\mathrm{g}}$ droop controller is turned on, which changes the generated power $P_{\mathrm{dc}}$ as a function of $V_{\mathrm{g}}$. This droop controller avoids violation of the grid voltage limits. The details of the controllers are depicted in Fig. 4. The $P_{\mathrm{dc}} / V_{\mathrm{g}}$ droop controller only changes $P_{\mathrm{dc}}$ if the microgrid voltage exceeds the adjustment voltages $V_{\mathrm{g} \text {,up }}$ and $V_{\mathrm{g}, \text { low }}$, which identify a voltage band that does not exceed the tolerated microgrid voltage band:

$$
P_{\mathrm{dc}}=\left\{\begin{array}{l}
P_{\mathrm{dc}, \text { nom }}-k\left(V_{\mathrm{g}}-\left(V_{\mathrm{g}, \text { nom }}+V_{\mathrm{g}, \mathrm{up}}\right)\right) \\
\quad \text { if } V_{\mathrm{g}}>V_{\mathrm{g}, \text { nom }}+V_{\mathrm{g}, \text { up }} \\
P_{\mathrm{dc}, \text { nom }} \\
\quad \text { if } V_{\mathrm{g}, \text { nom }}-V_{\mathrm{g}, \text { low }}<V_{\mathrm{g}}<V_{\mathrm{g}, \text { nom }}+V_{\mathrm{g}, \text { up }} \\
P_{\mathrm{dc}, \text { nom }}-k\left(V_{\mathrm{g}}-\left(V_{\mathrm{g}, \text { nom }}-V_{\mathrm{g}, \text { low }}\right)\right) \\
\quad \text { if } V_{\mathrm{g}}<V_{\mathrm{g}, \text { nom }}-V_{\mathrm{g}, \text { low }}
\end{array}\right.
$$

In case these adjustment voltages are not exceeded, $P_{\mathrm{dc}}$ remains unchanged and only the $V_{\mathrm{g}} / V_{\mathrm{dc}}$ droop control strategy is used. This operating condition is called operation in the "constantpower band", which has a width $2 b=V_{\mathrm{g}, \text { up }}+V_{\mathrm{g}, \text { low }}$.

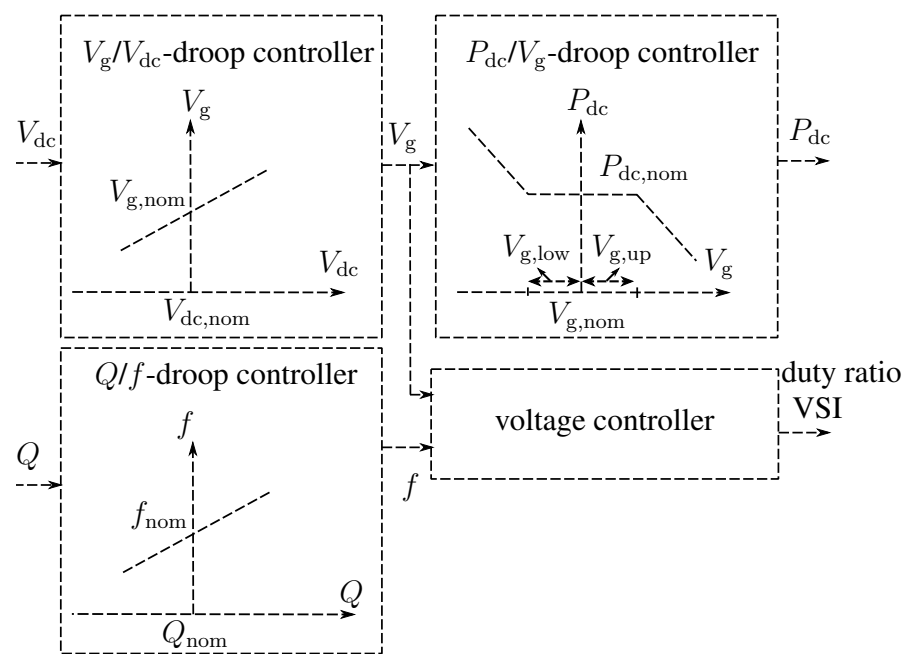

Fig. 4. Combined operation of the droop controllers to determine the set value of the grid voltage $v_{\mathrm{g}}$

\section{Characteristics}

The $V_{\mathrm{g}} / V_{\mathrm{dc}}$ control algorithm is fully distributed and deals with the specific properties of the microgrid, such as the lack of inertia and the resistive line characteristics. Also, the $V_{\mathrm{g}} / V_{\mathrm{dc}}$ droop control strategy is based on the (transient) storage capabilities of the dc-link capacitors and on the property that changes of $V_{\mathrm{dc}}$ indicate changes of the state of the microgrid power. The $V_{\mathrm{g}} / V_{\mathrm{dc}}$ droop control strategy delays changing the output power of the generators by slightly varying $V_{\mathrm{g}}$.

The $P_{\mathrm{dc}} / V_{\mathrm{g}}$ droop controller also avoids the usage of communication and central controllers, and is based on the resis- tive nature of the microgrid lines as well. If the dc-sources are current-controlled instead of power-controlled, analogous $I_{\mathrm{dc}} / V_{\mathrm{g}}$ droop controllers are used instead of the $P_{\mathrm{dc}} / V_{\mathrm{g}}$ droop controllers.

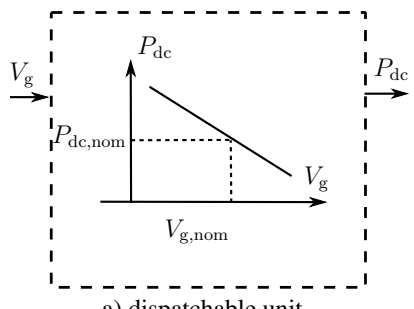

a) dispatchable unit

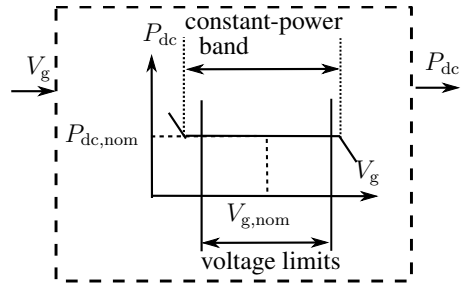

b) less controllable unit
Fig. 5. Fully dispatchable versus fully undispatchable DG unit. Dispatchable units have a small constant power band $(2 \mathrm{~b}=0 \%)$, fully undispatchable DG units have a very wide constant-power band.

The adjustment voltages $V_{\mathrm{g} \text {,up }}$ and $V_{\mathrm{g} \text {,low }}$ depend on the characteristics of the power source. For example, a distinction can be made between dispatchable and undispatchable power sources. For dispatchable (controllable, often non-renewable) power sources, a narrow constant-power band can be handled (cf. Fig. 5a). Therefore, small variations of $V_{\mathrm{g}}$ from $V_{\mathrm{g}, \text { nom }}$ address the $P_{\mathrm{dc}} / V_{\mathrm{g}}$ droop controller to change $P_{\mathrm{dc}}$. This enables to fully exploit the power control characteristics of the power source and the power source acts dynamically to limit the voltage changes by changing its output power.

For undispatchable power sources (slightly or not controllable, often intermittent renewable or combined heat and power units with heat as primary driver), $P_{\mathrm{dc}}$ is determined externally and therefore, a wide constant-power band must be applied. In the example of Fig. 5p, the constant-power band of the fully undispatchable DG unit is wider than the voltage limits. Thus, the output power is determined by the primary energy source ( $P_{\text {nom }}$, often with optimal power-point tracking), not by the state of the microgrid. For slightly dispatchable DG units, the limit $V_{\mathrm{g} \text {,up }}$ can be chosen smaller than the microgrid voltage limit. For example, many renewable sources can deviate from maximum power if necessary or heat-driven CHP units can change to electric power-driven mode, e.g. through thermal storage in a boiler. Because of the increasing share of renewable energy sources, active dispatching of these units in small-scale microgrids will be required, e.g. to avoid over-voltage tripping. An example to make the generated power of wind turbines or photovoltaic generators controllable is by including hybrid power systems, e.g., by combining the generators with energy storage systems and power management strategies [40], [41]. The reference power in this power management strategy comes from the $P_{\mathrm{dc}} / V_{\mathrm{g}}$ droop controller. The voltage-based droop control strategy makes active dispatching of the renewable energy possible, while still, the power changes of the renewables are delayed compared to those of the other DG units.

In conclusion, with a proper combined usage of $V_{\mathrm{g}} / V_{\mathrm{dc}}$ and $P_{\mathrm{dc}} / V_{\mathrm{g}}$ droop controllers, a higher degree of renewables and a more efficient usage of the renewable energy can be achieved. The reason is the usage of different adjustment voltages according to the characteristics of the DG units. Therefore, the changes of $P_{\mathrm{dc}}$ in the slightly-controllable units 
are delayed compared to the more dynamical DG units. The tolerance band of the microgrid voltage compared to its nominal value is effectively used, while still, violation of the voltage limits is avoided. Furthermore, the $V_{\mathrm{g}} / V_{\mathrm{dc}}$ droop and $P_{\mathrm{dc}} / V_{\mathrm{g}}$ droop control strategies deal with the specific properties of the microgrid and are fully distributed. Also, this active power control strategy of the generators allows to use the microgrid voltage as a trigger for possible active load control as discussed in $\$$ I-C. It also allows to use a PCC tap-changing ST to change the power exchange between a microgrid and the utility grid, without communication to the DG units in the microgrid. This is explained in $\$$

\section{B. Reactive power control of the generators}

In the islanded mode of the microgrid, the reactive power of the DG units is shared by using reactive power/grid frequency droop controllers:

$$
f=f_{\text {nom }}+K_{Q}\left(Q-Q_{\text {nom }}\right)
$$

with $f$ the VSI frequency that dynamically determines its phase angle, $Q$ the reactive power at the VSI terminals. In this way, in the islanded mode, the frequency will be determined by the total reactive power and reactive power sharing can also operate without inter-unit communication.

\section{Demand dispatch in the islanded microgrid}

By using the aforementioned active power control method for the generators, the possibility of the microgrid rms voltage to vary within certain limits is effectively used. Therefore, the microgrid voltage can be applied to communicate very high or very low levels of generated power in the islanded microgrid. These voltage changes are mainly due to the renewable power in case of proper application of the adjustment voltage. Hence, the rms microgrid voltage is also the trigger for the demand dispatch strategy in [37], which operates according to a relay function in Fig. 6. In case of high (renewable) production levels, the grid voltage increases, triggering some active loads to shift their consumption $P_{\text {load }}$ to high voltage times. For low voltage times, an analogous approach is followed. This demand dispatch is performed with the emphasis of increasing the reliability of the microgrid by providing assistance in the balancing, thus, it operates without communication. Therefore, if a remote communication signal for external demand control is lost, still, the presented demand dispatch, which is crucial in small islanded microgrids, can cooperate with the control of the generators to balance the power in the microgrid with a short response time.

This active load control based on the local microgrid voltage leads to a better usage of the available (renewable) energy because the consumers optimize their consumption according to the microgrid voltage level, which depends on the instantaneous production. For example, when customers shift their consumption towards high-voltage times, they mainly use renewable power because of the usage of generator-specific adjustment voltages. Secondly, a possible advantage is also the reduction of the line losses in the microgrid. E.g., if a renewable power source switches on, the closest loads will sense a higher

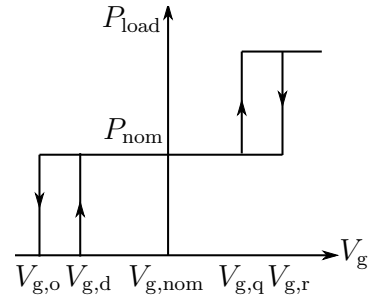

Fig. 6. Relay function for active load control

terminal voltage and therefore, shift their consumption in time. In this way, averaged over a specified time period and assumed that the total consumption for each load remains constant in this period, the consumption is temporarily shifted to zones with an instantaneous higher production, decreasing the overall line losses. Both advantages lead to an increased reliability and a better exploitation of the islanded microgrids.

\section{Virtual output impedances}

In this paper, current-controlled power sources are used in a mainly resistive microgrid. A control loop known as virtual output impedance loop has been proposed in literature to fix the output impedance of the inverter, to increase the stability of the system and to share linear and nonlinear loads. Therefore, virtual inductive, resistive and complex impedances $z_{v}$ can be used [42]-[44]. In this paper, a resistive output impedance $r_{v}$ is chosen as this provides more damping in the system [45] and complies with the power control strategies of the loads and generators, where the active power is changed based on the grid voltage:

$$
v_{\text {ref }}=v_{\text {droop }}-r_{v} i_{g},
$$

with $v_{\text {ref }}$ the reference voltage, $v_{\text {droop }}$ the voltage obtained by the droop controllers and $i_{g}$ the grid current.

\section{CONTROL OF POWER TRANSFER THROUGH SMART TRANSFORMER}

Because of the high share of intermittent power sources and the small scale of the microgrid, inducing possibly high load peaks, new means of power flexibility are required. The droop control of the DG units, active loads and storage can provide this. Another means to include flexibility is the usage of a smart transformer. The ST controls the active power exchange between a microgrid and the utility grid dependent on the state of both networks and other information communicated to the ST. The voltage-based control of the ST is compatible with the voltage-based droop control of the units in the microgrid. Hence, the microgrid units can automatically respond to changes of ST set points and vice versa.

\section{Control strategy}

To change the active power exchange $\Delta P_{\mathrm{PCC}}$ between microgrid and utility grid, generally, a secondary control approach is used that communicates changes of the set points of the DG units $\Delta P_{\text {set,i, }}$, such that

$$
\Delta P_{\mathrm{PCC}}=\sum_{i=1}^{N} \Delta P_{\text {set }, \mathrm{i}} .
$$




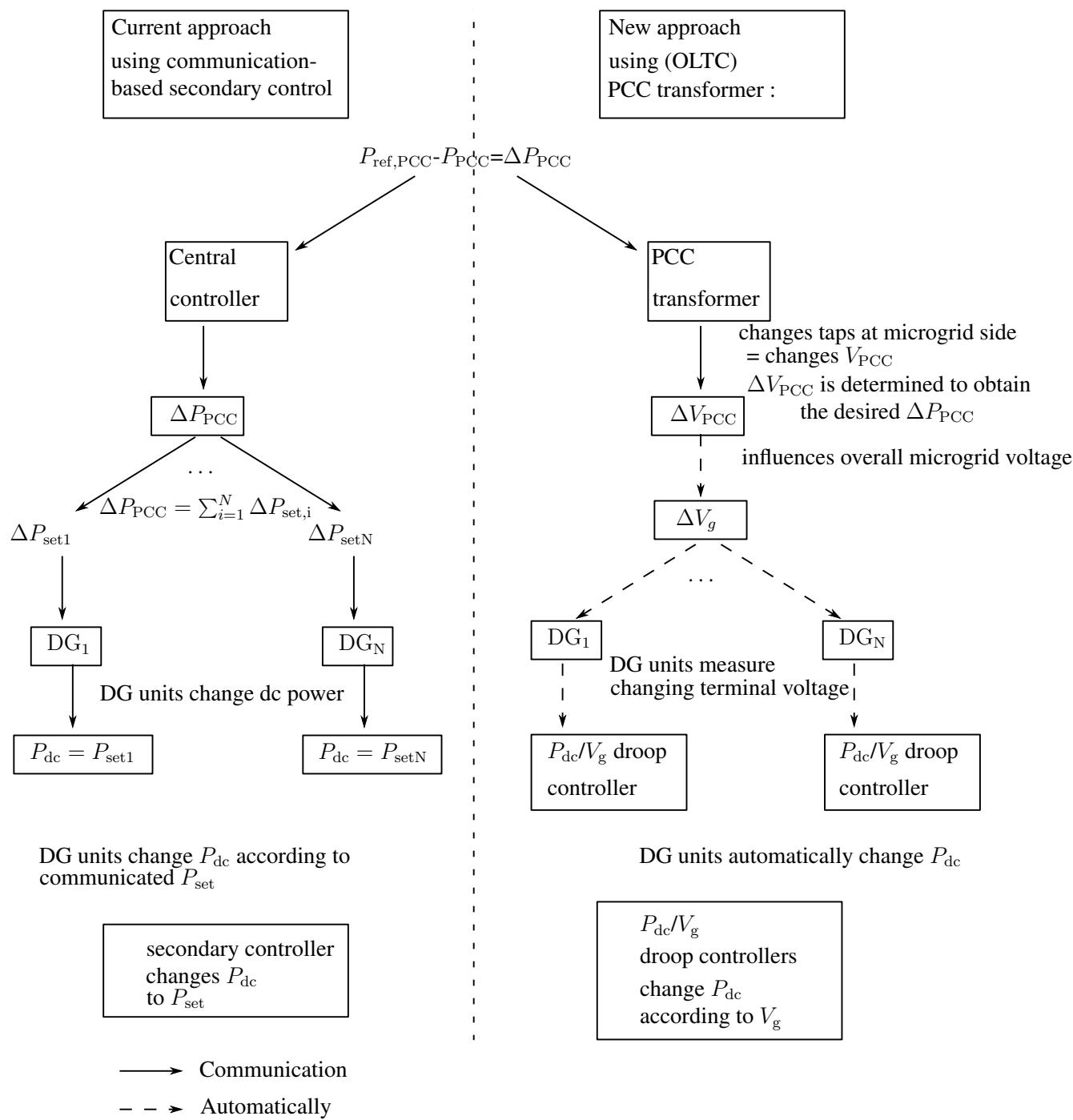

Fig. 8. Smart transformer versus central control to change power export from microgrid to utility network

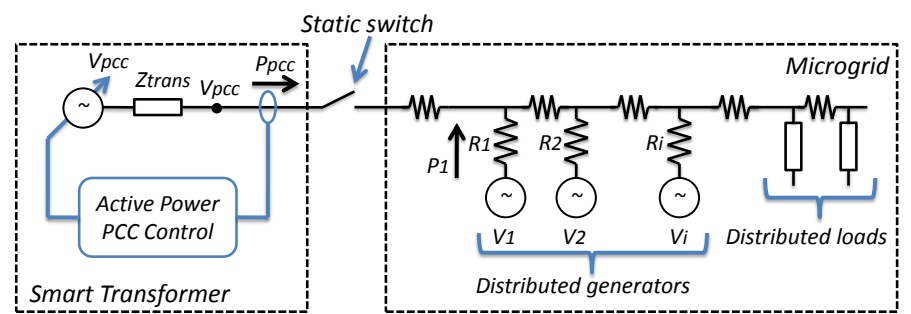

Fig. 7. Smart transformer with the equivalent circuits of the resistive virtual lines and the generators

Opposed to the general approach, in this paper, the power transfer between a microgrid and the utility grid is actively controlled without the need for communication to all microgrid elements. Instead, only $\Delta P_{\mathrm{PCC}}$ is communicated to the transformer that is often located at the PCC. This ST is depicted in Fig. 7 and a comparison between the central control strategy

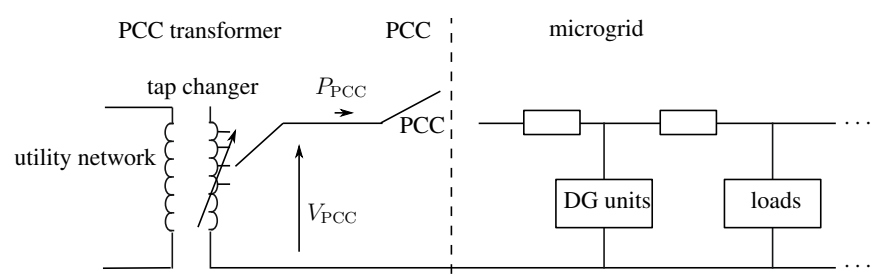

Fig. 9. Smart transformer in microgrid

and the ST strategy is shown in Fig. 8 The ST is an on-load tap changer (OLTC) as depicted in Fig. 9, that can change its microgrid-side taps to change the terminal voltage $V_{\mathrm{PCC}}$. The control algorithm of the ST is based on the following discrete PI controller to control $P_{\mathrm{PCC}}$ to $P_{\mathrm{PCC} \text {,ref }}$, Fig. 10 .

$$
V_{\mathrm{PCC}, \mathrm{k}}=V_{\mathrm{PCC}, \mathrm{k}-1}+\left(e_{k}-e_{\mathrm{k}-1}\right) K_{1}+e_{k} K_{2}
$$

with $e_{k}=P_{\mathrm{PCC}, \mathrm{ref}, \mathrm{k}}-P_{\mathrm{PCC}, \mathrm{k}}, V_{\mathrm{PCC}, \mathrm{k}}$ the STs secondary 


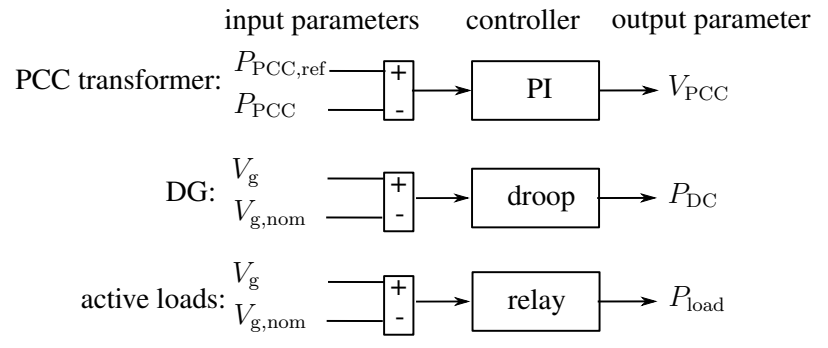

Fig. 10. PI controller for smart transformer

voltage and $k$ the discrete time step. The parameters $K_{1}$ and $K_{2}$ are derived from the proportional gain $K_{P}$ and the integral gain $K_{i}$ in a continuous PI controller by using:

$$
V_{\mathrm{PCC}}(t)=K_{p}\left(e(t)+\frac{1}{T_{i}} \int_{0}^{t} e(\tau) d \tau\right)
$$

which is transfered to discrete form by using backward finite difference:

$$
\frac{d V_{\mathrm{PCC}}(t)}{d t} \approx \frac{V_{\mathrm{PCC}, \mathrm{k}}-V_{\mathrm{PCC}, \mathrm{k}-1}}{\Delta t} .
$$

From this, it follows that $K_{1}=K_{p}$ and $K_{2}=K_{P} \Delta t / T_{i}$. A higher power transfer from utility grid to microgrid, $P_{\mathrm{PCC}}$, can be achieved by increasing $V_{\mathrm{PCC}}$, while of course, a lower $V_{\mathrm{PCC}}$ has the opposite effect.

A consequence of a higher $V_{\mathrm{PCC}}$, for example, is that the overall voltage in the microgrid will increase. Therefore, the difference between the DG units terminal voltages and the overall microgrid voltage will decrease. The DG units will, in this transient effect, deliver less ac power to the microgrid. Because initially, the dc-power remains the same, the dc-link voltage will increase. This increase will be sensed by the $V_{\mathrm{g}} / V_{\mathrm{dc}}$ droop controllers of the DG units, increasing their terminal voltage $V_{\mathrm{g}}$. The $P_{\mathrm{dc}} / V_{\mathrm{g}}$ droop controllers in turn will decrease the dc-power in response to the increased $V_{\mathrm{g}}$. In this way, the DG units automatically deliver less power when the power import to the microgrid is increased by increasing $V_{\mathrm{PCC}}$ with the ST.

Summarized, the power transfer $P_{\mathrm{PCC}}$ is altered by communicating $P_{\text {ref,PCC }}$ to the ST. This ST uses a tap changer to influence its microgrid-side voltage $V_{\mathrm{PCC}}$. This directly influences the active power in the microgrid because 1) it is a low-voltage network with mainly resistive line parameters, leading to a linkage between $P$ and $V, 2$ ) the active power control of both the generators and the active loads is voltagebased. Because the active power controllers of the DG units in the microgrid are voltage-triggered, the DG units automatically adapt. Therefore, $P_{\text {ref,PCC }}$ only needs to be communicated to a single unit and the rest of the microgrid adapts without communication. In this way, the microgrid can be exploited as a controllable entity within the electrical network for the primary control. One remark is that secondary control, communicating to more microgrid elements, can also be used, e.g., for optimization of the microgrid and economical issues.

2. Reference power exchange between microgrid and utility network
The reference power exchange $P_{\mathrm{PCC} \text {,ref }}$ can be altered depending on 1) the status of the main grid, 2) the status of the microgrid (in case voltage-based control strategies are implemented, this state is visible in the microgrid voltage), 3) communication delivered by, e.g., a central controller (timedependent price information, enabled by the smart grid concept). Overall, this information can be either communicationbased or voltage-based. In case of voltage-based information, the microgrid-side voltage is used as the trigger to change $P_{\mathrm{PCC} \text {,ref. }}$ The smart transformer is smart in the sense that this voltage-based strategy can be implemented in a $P_{\mathrm{PCC}, \text { ref }} / V_{\mathrm{PCC}}$ droop controller that does not require communication and is analogous to the $P_{\mathrm{dc}} / V_{\mathrm{g}}$ droop control of the DG units. In this way, the utility can (help) supply the balance of power in the microgrid by using the voltage-based method. In case of the communication-based information, in literature already some methods that determine OLTC set points are discussed, such as [46], [47]. These methods use an optimized power flow algorithm and an active management scheme. Also, in case of multiple microgrids, each microgrid can be seen as a single entity providing ancillary services, such as frequency regulation [48]. This frequency regulation can be coordinated between the microgrids by means of communication resulting in new power set points for the ST. The ST aggregates all the available information, both voltage-based and communication-based, to determine a reference power transfer $P_{\mathrm{PCC} \text {,ref }}$ between the main grid and the microgrid. The determination of $P_{\mathrm{PCC}, \mathrm{ref}}$ is not the focus of this paper and the communication-based method is used for this.

\section{Discussion}

This control algorithm has several advantages:

1) By using a controlled tap-changing ST located at the PCC in the grid-connected mode, the microgrid operates in a virtually islanded mode. This means that the microgrid elements can use the same control strategy both in gridconnected and islanded mode.

2) The control strategy of the smart transformer is compatible with the control of the loads and generators, because they are all voltage-based.

3) For $P_{\mathrm{PCC}}$ control, only communication between the utility grid and the smart transformer is required.

4) The microgrid adapts automatically to changes in the power transfer $P_{\mathrm{PCC}}$. Therefore, the usage of a ST enables one of the main advantages of microgrids, namely that the microgrid can be seen as a controllable entity from the utility grids point of view

A disadvantage is that the reactive power control strategy in the microgrid must be changed when using the ST. In the islanded mode with $Q / f$ droop control, the frequency is determined by the total reactive power. In the grid-connected mode with ST on the other hand, the microgrid frequency follows the grid frequency. As this can be assumed largely constant and nominal, all units operate at nominal reactive power. Generally, this involves unity power factor operation. However, by using low-bandwidth communication, the reactive power of the DG units can be altered by changing the nominal $Q$ or $f$ set points, this can be included in a secondary control strategy, which is out of scope of this paper. 
Another option would be the usage of a back-to-back (ac to ac) converter [49]. This configuration has an energy buffer in a dc-link capacitor, thus, gives more control flexibility. Also, opposed to a transformer, a back-to-back converter can control the microgrid frequency. Therefore, the converter can alter the reactive power exchange between the microgrid and the main grid even if the $Q / f$ droop control of the DG units is kept in the grid-connected mode. A back-to-back converter further renders dynamic decoupling to prevent voltage and frequency fluctuation in the utility side to impact the microgrid loads. The tap-changing ST only renders dynamic decoupling for voltage changes, not for frequency changes. Still, the frequency fluctuation in the utility network is rather small, while voltage fluctuations are more common, and would be severe because of the active power/voltage linkage in the low-voltage microgrid. The main disadvantage of a back-to-back converter is its high cost, because of the large rated power. This makes it impracticable for the power exchange control discussed in this paper.

\section{PROOF OF CONCEPT}

For a proof of concept, a basic microgrid is simulated, with simulations upto the level of the converter switches. The simulation parameters are summarized in Table I The active power and voltage controllers start at $t=0 \mathrm{~s}$ with $V_{\mathrm{g}}=230 \mathrm{~V}$ rms.

The microgrid consists of one ST located at the PCC, two DG units and two loads, as depicted in Fig. 11. Both DG units apply the $V_{\mathrm{g}} / V_{\mathrm{dc}}$ droop and $I_{\mathrm{dc}} / V_{\mathrm{g}}$ droop control strategies. The first DG unit, G1, has a wide constant-power band $2 b$ of $16 \%$, representing a slightly controllable DG unit, e.g., a renewable energy source with small storage capabilities. In this paper, the changes of, e.g., wind or sun, changing $I_{\mathrm{dc}}$ are not taken into account. The second one, G2, has a constant-power band $2 b$ of $0 \%$, thus, represents a highly dispatchable unit. The dynamic effects of the changes of $I_{\mathrm{dc}}$ of this unit are not modelled in detail, the simplest way to do so is by including a low-pass filter that slows down the obtained changes of $I_{\mathrm{dc}}$. Here, the low-pass filter is omitted. The nominal input dc-currents are $1.5 \mathrm{~A}$ and 3 A for $\mathrm{G} 1$ and $\mathrm{G} 2$ respectively. Both loads are resistive loads. Furthermore, virtual output impedance behavior is included and the line impedances are purely resistive. The latter is a valid assumption as generally, the low-voltage microgrid lines are mainly resistive, and this effect is increased by the resistive virtual output impedance. In [29], some inductance is included in the lines and this still shows a stable operation.

Three situations, depending on the reference active power through the ST, $P_{\text {ref }}$, are investigated. Again, the method to determine $P_{\mathrm{PCC}, \text { ref }}$, e.g. based on an optimal power flow algorithm, is not considered.

- $P_{\text {PCC,ref }}=800 \mathrm{~W}$ in Fig. 12 This simulation shows that the ST can track a reference active power by changing its microgrid-side voltage. Also, because of the voltage-based control of the DG units and the ST, the microgrid automatically responds to changes of the ST. The microgrid imports relatively much power from the main grid, for example, because of low energy prices in the main grid or off-times for the intermittent DG units in the microgrid. The obtained steady-state results are summarized in

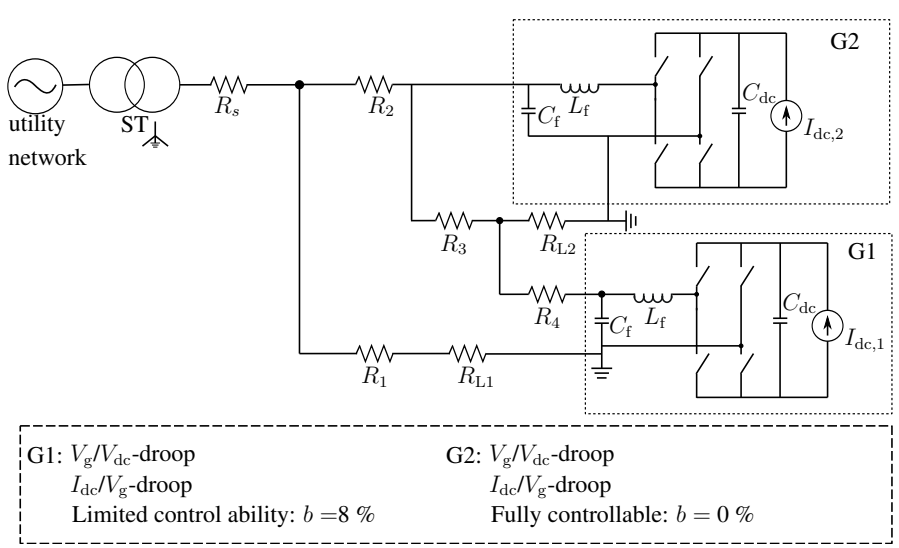

Fig. 11. Microgrid configuration for proof of concept using smart transformer: single-line diagram

TABLE I

SYSTEM PARAMETERS. THE LINE PARAMETERS ARE BASED ON BAXB CABLES WITH PHASE RESISTANCE $0.41 \Omega / k m$ AND NEUTRAL CONDUCTOR WITH $0.71 \Omega / k m$ AND $R_{\text {phase }} / X \approx 5$.

\begin{tabular}{|l|l||l|l|}
\hline parameter & value & parameter & value \\
\hline$f_{\mathrm{s}, \mathrm{VSI}}$ & $20 \mathrm{kHz}$ & $C_{\mathrm{f}}$ & $3 \mu \mathrm{F}$ \\
$f_{\mathrm{s}, \mathrm{ST}}$ & $1 \mathrm{kHz}$ & $L_{\mathrm{f}}$ & $2 \mathrm{mH}$ \\
$R_{1}$ & $0.5 \Omega$ & $C_{\mathrm{dc}}$ & $1.5 \mathrm{mF}$ \\
$R_{2}$ & $0.1 \Omega$ & Droop $a$ & $0.5 \mathrm{~V} / \mathrm{V}$ \\
$R_{3}$ & $0.3 \Omega$ & Droop $K_{Q}$ & $5 \mathrm{e}^{-5} \mathrm{~Hz} / \mathrm{VAr}$ \\
$R_{4}$ & $0.3 \Omega$ & Droop k & $I_{\mathrm{dc}, \mathrm{nom}} / 50$ \\
$R_{5}$ & $0.3 \Omega$ & $f_{\text {nom }}$ & $50 \mathrm{~Hz}$ \\
$R_{\mathrm{L} 1}$ & $33 \Omega$ & $Q_{\mathrm{nom}}$ & $0 \mathrm{VAr}$ \\
$R_{\mathrm{L} 2}$ & $33 \Omega$ & $I_{\mathrm{dc}, \text { nom }, 1}$ & $1.5 \mathrm{~A}$ \\
$r_{\mathrm{v}}$ & $3 \Omega$ & $I_{\mathrm{dc}, \text { nom }, 2}$ & $3 \mathrm{~A}$ \\
$V_{\mathrm{dc}, \text { nom }}$ & $450 \mathrm{~V}$ & $V_{\mathrm{g}, \text { nom }}$ & $230 \mathrm{~V} \mathrm{rms}$ \\
\hline
\end{tabular}

Table II The input dc-current of G1 remains $1.5 \mathrm{~A}$ as its terminal voltage, namely $226.8 \mathrm{~V}$ remains in the constantpower band of $\left[(1-b) V_{\mathrm{g}, \mathrm{nom}},(1+b) V_{\mathrm{g}, \mathrm{nom}}\right]$ or [211.6, 248.4] V. The input dc-current of G2 is slightly increased to $3.26 \mathrm{~A}$ as this power source has a constant-power band $2 b$ of $0 \%$ and its terminal voltage is slightly lower than the nominal voltage.

- $P_{\text {PCC,ref }}=0 \mathrm{~W}$ in Fig. 13 The smart transformer controls its secondary rms voltage such that there is no active power exchange between the main grid and the virtually islanded microgrid. Still, the PCC switch is closed, so reactive power exchange between both networks is possible.

As depicted in Table III, the terminal voltage of the ST is lower to obtain a lower $P_{\mathrm{PCC}}$ compared to the case of Fig. 12 This low ST voltage influences the voltages of the rest of the microgrid. Hence, a lower terminal voltage $V_{\mathrm{g}, 2}$ is obtained, and therefore, the flexible DG unit G2 increases the delivered dc-current. The inflexible unit G1 on the other hand, delivers nominal dc-current of 1.5 A because the grid voltage remains in the constantpower band. Furthermore, compared to the case with 


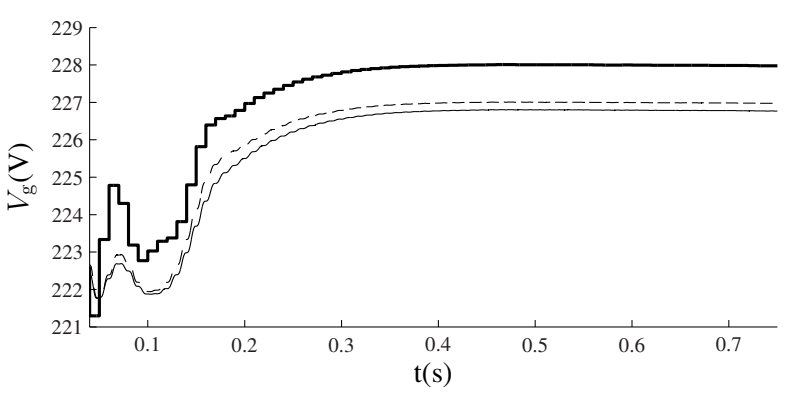

(a) Microgrid rms voltage

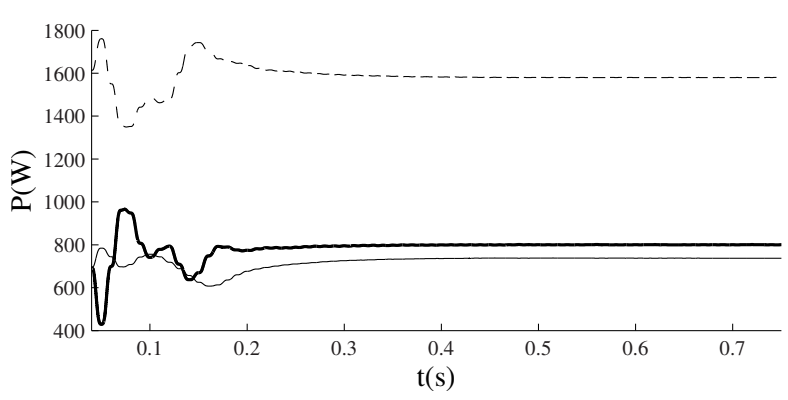

(b) Active power to the electrical network

Fig. 12. Influence of smart transformer with $P_{\mathrm{PCC}, \text { ref }}=800 \mathrm{~W}(-=\mathrm{G} 1$; ---- = G2; - = smart transformer)

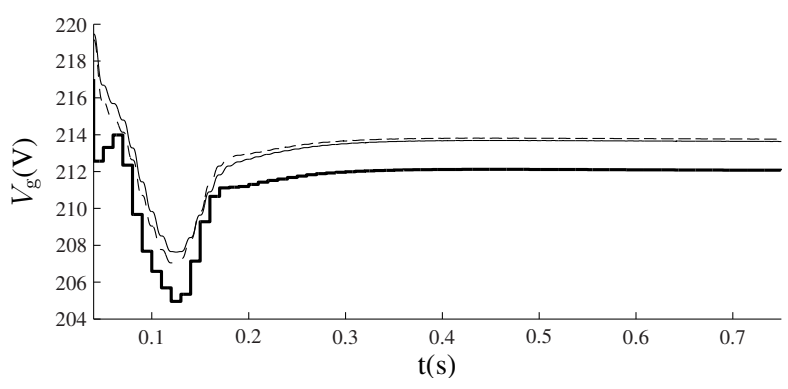

(a) Microgrid rms voltage

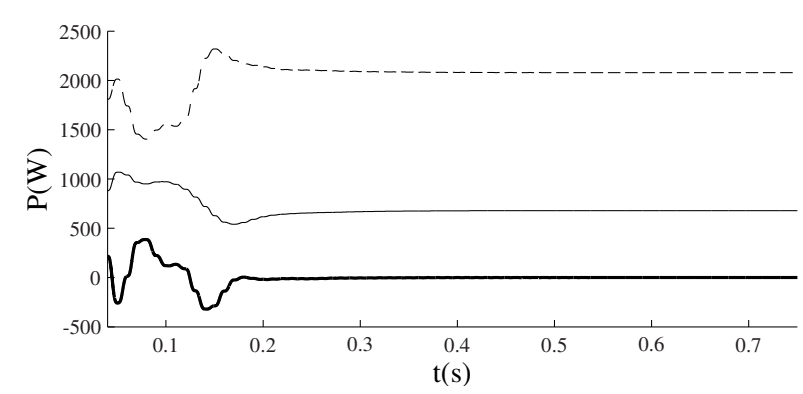

(b) Active power to the electrical network

Fig. 13. Influence of smart transformer with $P_{\mathrm{PCC}, \text { ref }}=0 \mathrm{~W}(-=\mathrm{G} 1$; ---$=\mathrm{G} 2 ;-=$ smart transformer)

$P_{\text {PCC,ref }}=800 \mathrm{~W}$, the current-controlled source G1 delivers less power to the microgrid, because the lower microgrid voltage combined with the $V_{\mathrm{g}} / V_{\mathrm{dc}}$ droop control leads to lower dc-link voltages.

This simulation shows that the microgrid automatically adapts to the STs' secondary voltage and that the ST can significantly influence the microgrid state.
TABLE II

OVERVIEW: INFLUENCE OF POWER EXCHANGE THROUGH SMART TRANSFORMER

\begin{tabular}{|c|ccc|}
\hline & \multicolumn{3}{|c|}{$P_{\text {ref,PCC }}$} \\
& $800 \mathrm{~W}$ & $0 \mathrm{~W}$ & $-800 \mathrm{~W}$ \\
\hline$P_{1}(\mathrm{~W})$ & 737 & 678 & 789 \\
$P_{2}(\mathrm{~W})$ & 1580 & 2078 & 2500 \\
$P_{\mathrm{PCC}}(\mathrm{W})$ & 800 & 0 & -800 \\
\hline$V_{1}(\mathrm{~V})$ & 226.8 & 213.6 & 202.9 \\
$V_{2}(\mathrm{~V})$ & 227.0 & 213.8 & 202.5 \\
$V_{\mathrm{PCC}}(\mathrm{V})$ & 228.8 & 212.1 & 197.6 \\
\hline$I_{\mathrm{dc}, 1}(\mathrm{~A})$ & 1.5 & 1.5 & 1.87 \\
$I_{\mathrm{dc}, 2}(\mathrm{~A})$ & 3.26 & 4.38 & 5.34 \\
\hline
\end{tabular}

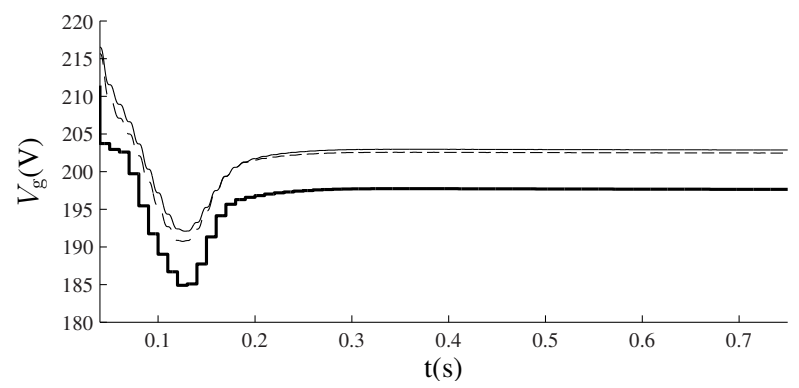

(a) Microgrid rms voltage

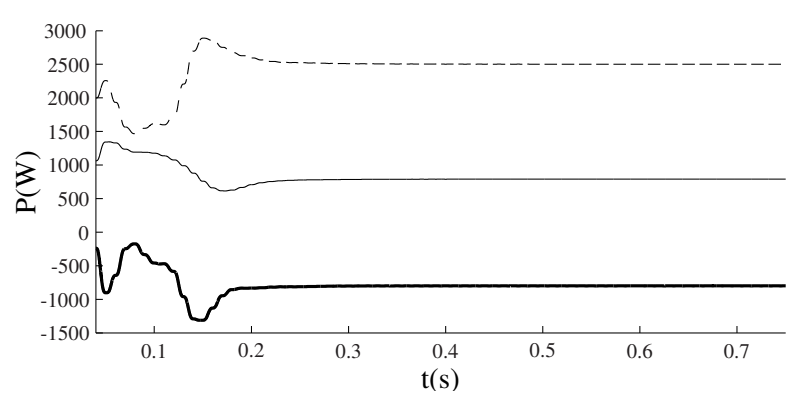

(b) Active power to the electrical network

Fig. 14. Influence of smart transformer with $P_{\mathrm{PCC}, \text { ref }}=-800 \mathrm{~W}(-=$ $\mathrm{G} 1 ;----=\mathrm{G} 2 ;-=$ smart transformer )

- $P_{\mathrm{PCC}, \mathrm{ref}}=-800 \mathrm{~W}$ in Fig. 14. The islanded microgrid delivers active power to the main grid. The same trend as in the previous case is concluded: more power is generated in the microgrid because of the power export to the main grid. Opposed to the previous cases, the terminal grid voltages of both power sources are under the lower adjustment voltage, so both sources increase their dc-current. This shows the advantage of using the $I_{\mathrm{dc}} / V_{\mathrm{dc}}$ droop control with generator-dependent width of the constant-power band: the change of the dc-current of the inflexible DG unit G1 is delayed compared to that of the more flexible unit $\mathrm{G} 2$.

In the previous simulations, the voltage limits and usage of energy storage are not taken into account such that more extreme voltages compared to practical situations can be obtained, which is also due to the small scale of the simulated microgrid. In this way, the effect of the ST and changes of 
the DG units can be studied. To take these voltage limits into account, the control signals of the ST can be influenced by the voltage state of the microgrid and active load control and storage can be included, which is not the case in the previous simulation. Also, a microgrid with only two DG units, one of them being inflexible was studied, so more flexibility in the DG units would lead to voltages closer to the nominal value.

In conclusion, by implementing the smart tap-changing transformer in the microgrid, the power exchange between a microgrid and the utility grid can be controlled by changing the microgrid-side voltage of the ST. It is also shown that the microgrid generators automatically (without need for communication) change their output powers according to the microgridside voltage of the ST. In this way, the ST can significantly influence the microgrid state.

\section{SMART TRANSFORMER DELIVERS INCREASED FLEXIBILITY TO THE MICROGRID}

In this simulation example, a more realistic microgrid (four generators, different loads, smart transformer) is studied. The main purpose of this simulation is 1) to study the ST operation in the microgrid, 2) to compare the cases of real islanded microgrid and a grid-connected microgrid. The microgrid configuration is depicted in Fig. 15. The microgrid sources have the following characteristics:

- G1

Constant-current source with a nominal dc-current $I_{\mathrm{dc}, \text { nom }}$ of $6 \mathrm{~A}$. The active power control is performed by the $V_{\mathrm{g}} / V_{\mathrm{dc}}$ droop controller only, thus, a very large constantpower band is included. For example, G1 can represent a renewable energy source.

- $\mathrm{G} 2$

G2 uses $V_{\mathrm{g}} / V_{\mathrm{dc}}$ and $P_{\mathrm{dc}} / V_{\mathrm{g}}$ droop control strategy and has limited control flexibility. Therefore, a constant-power band $2 b=10 \%$ is included. The nominal power of this power-controlled source equals $P_{2, \text { nom }}=3000 \mathrm{~W}$.

- G3

Current-controlled source with $V_{\mathrm{g}} / V_{\mathrm{dc}}$ and $I_{\mathrm{dc}} / V_{\mathrm{g}}$ droop control and $I_{3, \text { nom }}=5 \mathrm{~A}$, constant-power band $2 b=$ $6 \%$. This constant-power band can be included in a semidispatchable unit, for example a CHP unit with heat as the primary driver, but in case of extreme terminal voltages, electric power can become the primary driver.

- G4

$V_{\mathrm{g}} / V_{\mathrm{dc}}$ and $I_{\mathrm{dc}} / V_{\mathrm{g}}$ droop control, fully flexible currentcontrolled source as the constant-power band $2 b$ equals $0 \%$ representing a fully dispatchable DG unit, $I_{3, \text { nom }}=$ $3.5 \mathrm{~A}$.

Here, only linear loads are included as the focus is on the ST, not on the active power controllers. An analogous microgrid with nonlinear loads and inductive line elements has been considered in [29]. The system parameters are equal as in the previous simulation, and are summarized in Table 1

\section{A. Case without smart transformer}

In this simulation case, the switch at the PCC is open, thus, an islanded microgrid is obtained.

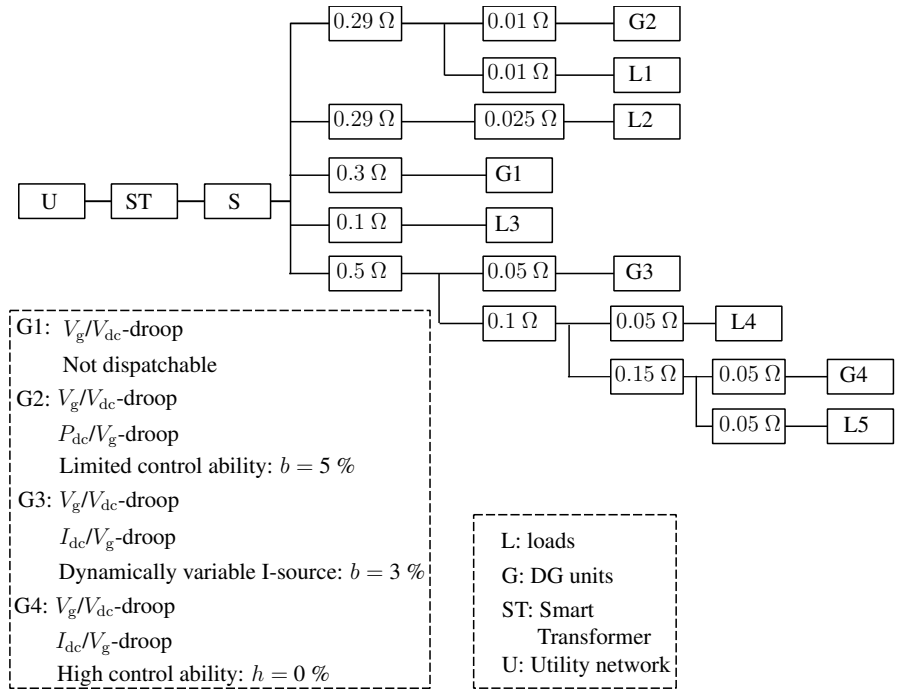

Fig. 15. Microgrid configuration successive comparison by including a smart transformer and demand dispatch

The simulation results in Fig. 16 show a stable microgrid operation. From the simulations, it follows that, as G1 has no control flexibility, its dc-current remains the nominal value of 6 A. G2 on the other hand, which has some control flexibility, increases its output power from nominal $3000 \mathrm{~W}$ to $3122 \mathrm{~W}$ as its terminal voltage is lower than the lower adjustment voltage of $0.95 V_{\mathrm{g}, \text { nom }}=218.5 \mathrm{~V}$. The same is valid for G3 and G4.

Note that in this case, low generated powers are chosen to obtain low output voltages. In this way, the impact of more control flexibility, namely the ST can be studied in detail in the next case. Still, a proper microgrid operation is obtained, despite the small scale of the microgrid, the very low control flexibility in the generators and the ignored impact of energy storage and active load control.

\section{B. Case with smart transformer}

In this simulation case, the PCC switch is closed to operate the microgrid in a grid-connected mode. Because of the low voltages obtained in the previous case, the reference power import in the microgrid, through the ST, equals $500 \mathrm{~W}$ (which is a chosen value dependent on the microgrid state only). Also, the same communication-less control strategy of the DG units is used as in the previous case. The simulation results are shown in Table III and Fig. 17

Compared to the simulation case without ST, the terminal voltages of all units are higher, thus closer to the nominal value, because of the power import through ST. The simulations also show that slightly more power is delivered by some DG units. The reason is that the ST increases the microgrid voltage and most generators here use current-controlled energy sources. For example, for the current-controlled source G1, because of the $V_{\mathrm{g}} / V_{\mathrm{dc}}$-droop control, an increase of $V_{\mathrm{g}}$ leads to higher $V_{\mathrm{dc}}$. As the dc-link voltages increases, under constant $I_{\mathrm{dc}}$, also the dc-power increases. In this way, the delivered ac active power is slightly increased as well. Because of the higher terminal 


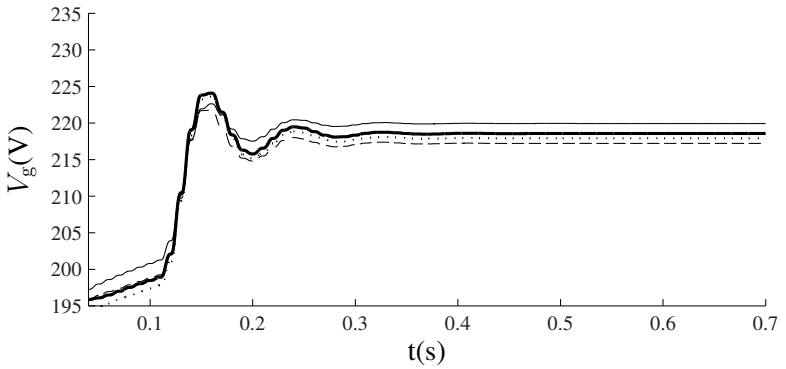

(a) Microgrid voltage

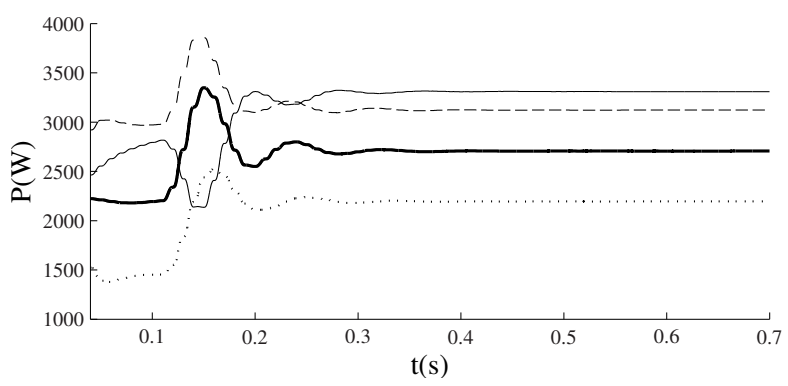

(b) Active power to the electrical network

Fig. 16. Smart transformer in microgrid: without smart transformer $(-=$ VSI $1 ;----=$ VSI $2 ;-=$ VSI $3, \ldots=$ VSI 4 )

TABLE III

OVERVIEW: SMART TRANSFORMER IN MICROGRID

\begin{tabular}{|c|cc|}
\hline & \multicolumn{2}{|c|}{$P_{\mathrm{PCC}, \text { ref }}$} \\
& no ST & with ST \\
\hline$P_{1}(\mathrm{~W})$ & 3308 & 3407 \\
$P_{2}(\mathrm{~W})$ & 3122 & 3040 \\
$P_{3}(\mathrm{~W})$ & 2706 & 2560 \\
$P_{4}(\mathrm{~W})$ & 2195 & 2121 \\
$P_{\mathrm{PCC}}(\mathrm{W})$ & - & 500 \\
\hline$V_{1}(\mathrm{~V})$ & 219.9 & 223.3 \\
$V_{2}(\mathrm{~V})$ & 217.2 & 220.3 \\
$V_{3}(\mathrm{~V})$ & 218.6 & 221.0 \\
$V_{4}(\mathrm{~V})$ & 217.9 & 220.2 \\
$V_{\mathrm{PCC}}(\mathrm{V})$ & - & 219.9 \\
$V_{\mathrm{L}, 1}(\mathrm{~V})$ & 213.3 & 216.6 \\
$V_{\mathrm{L}, 2}(\mathrm{~V})$ & 217.0 & 220.1 \\
\hline$I_{\mathrm{dc}, 1}(\mathrm{~A})$ & 6 & 6 \\
$I_{\mathrm{dc}, 2}$ & 6.3 & 6.1 \\
$I_{\mathrm{dc}, 3}(\mathrm{~A})$ & 5.6 & 5.3 \\
$I_{\mathrm{dc}, 4}$ & 4.7 & 4.5 \\
\hline
\end{tabular}

voltages compared to the previous case, the dc-input currents are lower than in the previous case.

The simulations indicate that the ST can control the power exchange between the microgrid and the main grid. Also, the ST can effectively increase the voltage quality in the microgrid by forcing the voltage closer to its nominal value. Because of the ST, there is no need to change the power control method of the DG units in case of the islanded operating condition or the grid-connected operation with ST.

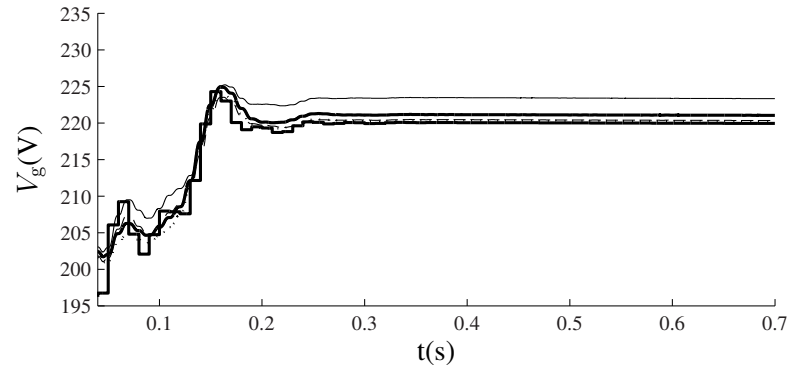

(a) Microgrid voltage

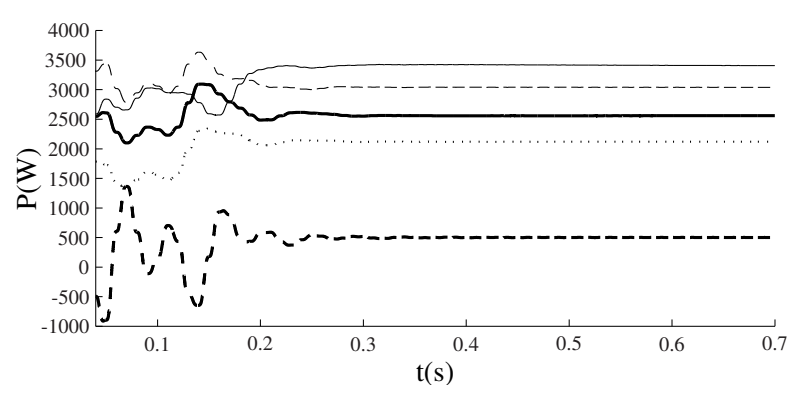

(b) Active power to the electrical network

Fig. 17. Smart transformer in microgrid: with smart transformer $(-=\mathrm{G} 1$ $---\mathrm{G} 2 ;-=\mathrm{G} 3, \ldots=\mathrm{G} 4, \mathrm{---}=$ smart transformer )

\section{SMART TRANSFORMER IN A MICROGRID WITH DYNAMICAL CHANGES}

In the following simulations, some dynamical events are included to study changing parameters in a microgrid that is connected to the utility network through a smart transformer. The microgrid configuration of Fig. 18 is studied. The simulation results are shown in Table III and Fig. 17. This microgrid consists of three power sources:

- G1

This power source fully operates with a combination of $V_{\mathrm{g}} / V_{\mathrm{dc}}$ droop control and $I_{\mathrm{dc}} / V_{\mathrm{g}}$ droop control. An example of this is a power source that is flexible in power change.

- G2

This power source applies the $V_{\mathrm{g}} / V_{\mathrm{dc}}$ droop control strategy if the microgrid voltage does not exceed the adjustment voltages of $V_{\text {nom }} \pm 1 \%$. Otherwise, the power control strategy is extended with $I_{\mathrm{dc}} / V_{\mathrm{g}}$ droop control. An example of this is a power source that has a limited flexibility (storage or fuel intake).

- G3

G3 operates at constant dc-current with a $V_{\mathrm{g}} / V_{\mathrm{dc}}$ droop control strategy. This can be a renewable energy source that operates according to a maximum-power point tracking (MPPT) algorithm. Of course, the dc-current can change because of external factors such as wind speed or solar irradiation, but not by the VSI control strategy itself. The only control ability possible in this power source is turning off in case of too high terminal voltages or a faulted electrical network. In practical applications however, it is recommended to follow the MPPT as long as possible, but with possibility to leave the MPPT algorithm 


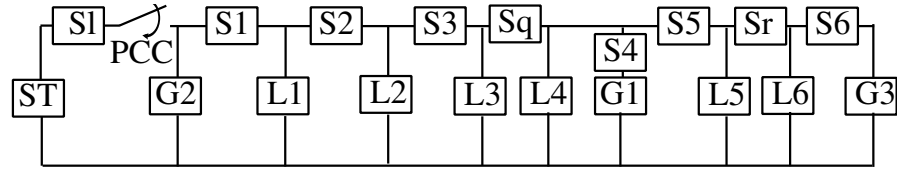

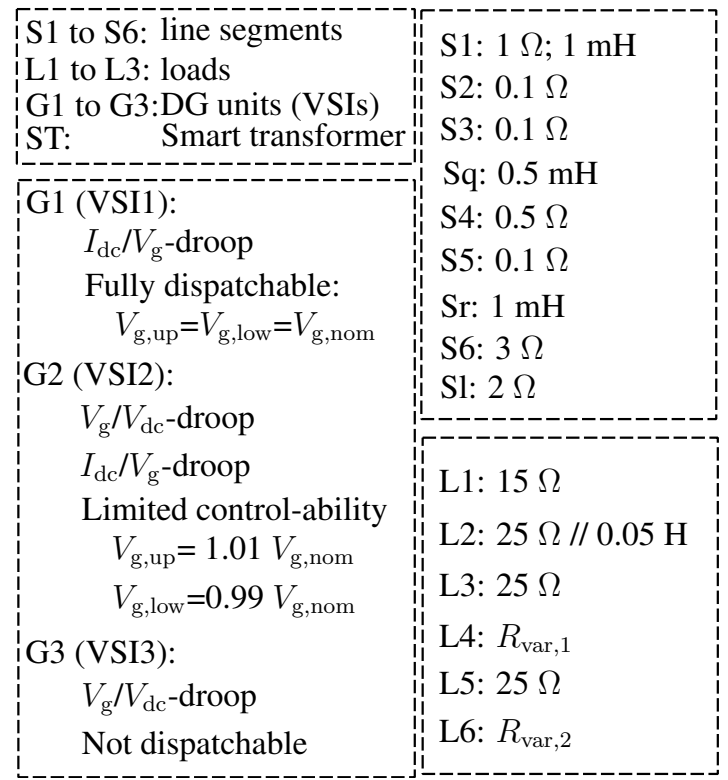

Fig. 18. Microgrid configuration: extended example

in case of extreme voltages. For example, in case the microgrid stability is jeopardized, the generator can also contribute in the power balancing by abandoning the MPPT. This can be realized by including a wide constantpower band. In this simulation however, as the smart transformer is studied, this VSI 3 does not contribute to the power balancing.

In the following simulations, the nominal generated dc-currents are: $I_{\mathrm{dc}, 1}=7 \mathrm{~A}, I_{\mathrm{dc}, 2}=4.5 \mathrm{~A}$ and $I_{\mathrm{dc}, 3}=3.5 \mathrm{~A}$. For the reactive power control, $Q / f$ droop control is applied, with equal droops for the power sources. The loads considered here are a combination of variable and non-variable loads. The simulations mimic a dynamic profile, with dynamic events such as losing a generator and changing the demand dispatch. These dynamic events follow very quickly compared to an actual microgrid. The reason is to have shorter simulation times, as the steady-state conditions give no further information. Starting from $230 \mathrm{~V}$ without demand dispatch (DD), the dynamic events included in the following simulation are:

- $t=0 \mathrm{~s}$ : all VSIs operate at $100 \%$ (nominal) power;

- $t=0.35$ s: VSI 3 switches off;

- $t=0.36 \mathrm{~s}$ : start of the DD for both variable loads. Here basic DD is included: $R_{\mathrm{var}, 1}$ can change from $25 \Omega$ to $50 \Omega$ with $V_{\mathrm{g}, \mathrm{o}}=0.91 V_{\mathrm{g}, \text { nom }}$ and $V_{\mathrm{g}, \mathrm{d}}=0.96 V_{\mathrm{g}, \text { nom }}$ in the relay function of Fig. 6. The second load with DD $R_{\mathrm{var}, 2}$ can change from $25 \Omega$ to $5000 \Omega$ with $V_{\mathrm{g}, \mathrm{o}}=$ $0.93 V_{\mathrm{g}, \text { nom }}$ and $V_{\mathrm{g}, \mathrm{d}}=0.97 V_{\mathrm{g}, \text { nom }}$. The DD operates with a delay, for stability reasons, to include measurement and responsive delay and for practical reasons in the implementation in the loads.
- $t=0.70 \mathrm{~s}:$ VSI 3 starts operating at $50 \%$;

- $t=0.85 \mathrm{~s}$ : the DD turns off for the first variable load, such that $R_{\text {var, } 1}=25 \Omega$, as, e.g., its power consumption can not be delayed any further.

- $t=1 \mathrm{~s}$ : the nominal dc-current of VSI 2 falls down to $75 \%$.

In the simulations presented below, first, the islanded microgrid without smart transformer is studied. Secondly, this is compared with the case of a microgrid with smart transformer.

\section{A. Case without smart transformer}

The simulation results for the case without smart transformer and with open PCC switch are depicted in Fig. 19

- $0<t<0.35$ s: After a start-up transient, the terminal voltages reach $V_{\mathrm{g}, 1}=218 \mathrm{~V}, V_{\mathrm{g}, 2}=216 \mathrm{~V}$ and $V_{\mathrm{g}, 3}=$ $236 \mathrm{~V}$.

- $0.35<t<0.7 \mathrm{~s}$ : The demand signal for both variable loads turns on. Despite the loss of VSI 3, the contribution of the DD leads to a small voltage increase to $V_{\mathrm{g}, 1}=$ $218 \mathrm{~V}$ and $V_{\mathrm{g}, 2}=217 \mathrm{~V}$. For the same reason, the power sources deliver slightly less power to the microgrid. One remark according to the disconnection of G3 is that in the time span where G3 is turned off, the terminal voltage of this VSI slowly decreases. This has no practical value for the microgrid, as G3 is disconnected. The reason for this voltage decrease is that the disconnection of $\mathrm{G} 3$ is modelled with 1) $I_{\mathrm{dc}, 3}=0 \mathrm{~A}, 2$ ) a switch located after the LC filter of G3 opens. Therefore, the LC-filter is not supplied and the filter capacitor voltage decreases across parasitic resistances, which are here simulated as a large resistance in parallel with this capacitor.

Therefore, despite the loss of a DG unit, the active load control enables a stable microgrid operation.

- $0.7<t<0.85 \mathrm{~s}$ : Higher microgrid voltages are obtained because of the activation of VSI 3.

- $0.85<t<1 \mathrm{~s}$ : At $0.85 \mathrm{~s}$, the demand signal of $R_{\mathrm{var}, 1}$ is turned off, leading to a higher load burden. Therefore, the microgrid voltages are slightly decreased and G1 and G2 respond by increasing their output power.

- $t<1$ s: Because less power is delivered by G2, the microgrid voltages are lower compared to the previous time span: with $V_{\mathrm{g}, 1}=217 \mathrm{~V}, V_{\mathrm{g}, 2}=213 \mathrm{~V}$ and $V_{\mathrm{g}, 3}=220 \mathrm{~V}$. Furthermore, because of the lower $P_{2}, P_{1}$ increases. In steady-state also, $I_{\mathrm{dc}, 1}=9.5 \mathrm{~A}, I_{\mathrm{dc}, 2}=5.2 \mathrm{~A}$ and $I_{\mathrm{dc}, 3}=1.8 \mathrm{~A}$.

In general, by including the active load control depending on the microgrid voltage, the load can actively contribute to the stabilization of the microgrid.

\section{B. Case with smart transformer}

In this simulation, the feasibility of the smart transformer concept in a microgrid with dynamic events is studied. The reference power of the smart transformer starts at $800 \mathrm{~W}$. At $t=0.80 \mathrm{~s}, P_{\text {ref }}$ decreases to $-800 \mathrm{~W}$. Generally, the state of the microgrid influences $P_{\text {ref,PCC, e.g., by including }}$ $P_{\text {ref,PCC }}, / V_{\mathrm{PCC}}$ droop control in the $\mathrm{ST}$. However, in order to 


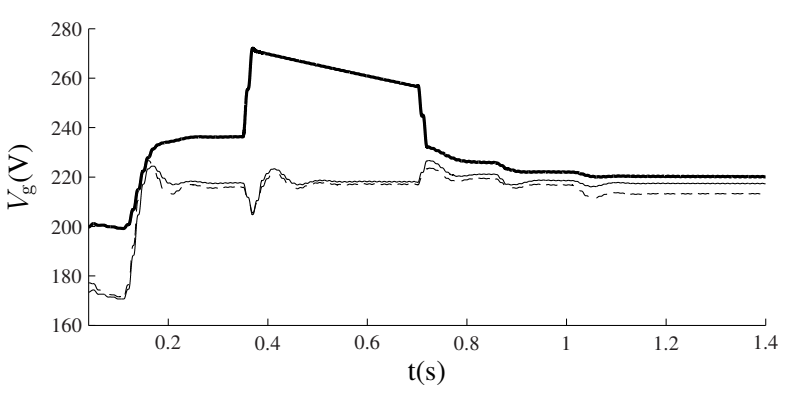

(a) Microgrid voltage

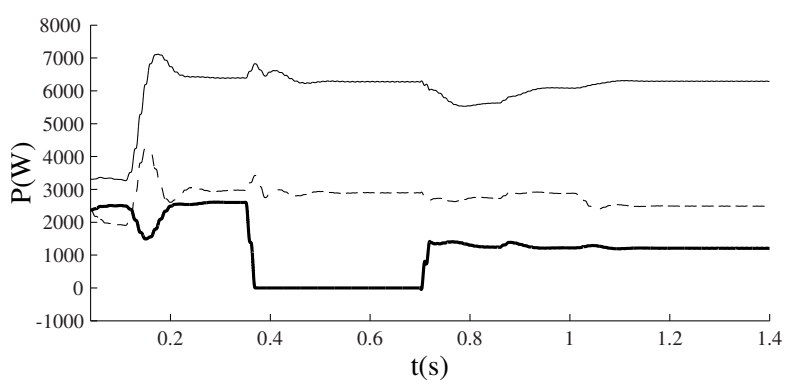

(b) Active power to the electrical network

Fig. 19. Dynamic profile: without smart transformer $(-=\mathrm{G} 1$; ---- $=\mathrm{G} 2$; $=\mathrm{G} 3$ )

study a more difficult case, here, $P_{\text {ref,PCC }}$ is determined by external information only.

The simulation results for the case with smart transformer are depicted in Fig. 20. From the simulations, it follows that in the first time span $0<t<0.35 \mathrm{~s}$, the terminal voltages are $V_{\mathrm{g}, 1}=219 \mathrm{~V}, V_{\mathrm{g}, 2}=221 \mathrm{~V}, V_{\mathrm{g}, 3}=238 \mathrm{~V}$ and $V_{\mathrm{g}, \mathrm{ST}}=228 \mathrm{~V}$. The obtained voltages are higher than in the previous case, because of the power input from the utility grid.

At $t=0.8 \mathrm{~s}$, the reference power of the smart transformer decreases significantly, which can be triggered by the utility network because of, e.g., a sudden loss of a generator. From the simulations, it follows that the dispatchable DG units increase their output power, without communication, to compensate for this change in the smart transformer. The voltage in the microgrid decreases, such that the microgrid will trigger the smart transformer to change $P_{\text {ref,PCC }}$ by means of $P_{\text {ref,PCC }} / V_{\mathrm{PCC}}$ droop control, in order to prevent under-voltage conditions. This is not included in this example in order to study the reaction of the DG units on the $P_{\text {ref,PCC }}$ change rendered by the utility network.

In steady-state, $V_{\mathrm{g}, 1}=215 \mathrm{~V}, V_{\mathrm{g}, 2}=209 \mathrm{~V}, V_{\mathrm{g}, 3}=216 \mathrm{~V}$ and the delivered dc-currents are: $I_{\mathrm{dc}, 1}=10.0 \mathrm{~A}, I_{\mathrm{dc}, 2}=5.8 \mathrm{~A}$ and $I_{\mathrm{dc}, 3}=1.8$ A. $I_{\mathrm{dc}, 1}$ and $I_{\mathrm{dc}, 2}$ are higher than in the previous case to compensate for the power export to the main grid.

In conclusion, the simulations indicate that the smart transformer is able to operate in a microgrid with dynamic events. By adapting its $P_{\text {ref,PCC }}$ to the microgrid state, a higher power quality (voltage quality) can be obtained. Furthermore, the microgrid generators and active loads automatically adjust to state of the smart transformer.

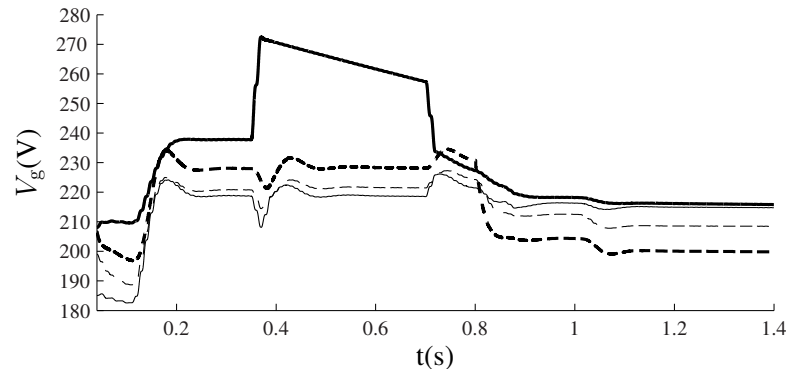

(a) Microgrid voltage

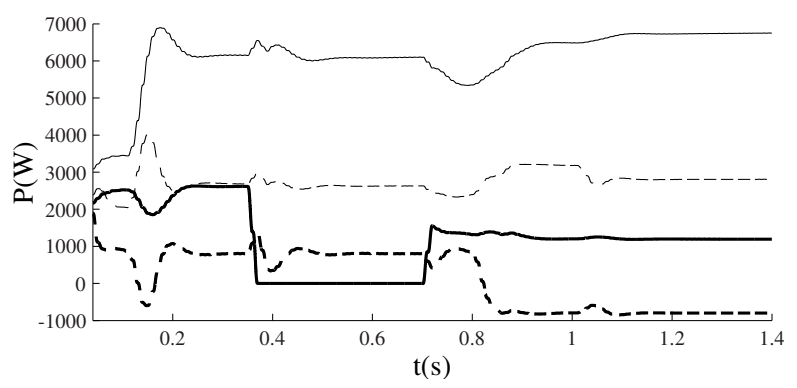

(b) Active power to the electrical network

Fig. 20. Dynamic profile: with smart transformer $(-=\mathrm{G} 1$; ---- = G2; = G3, --- = smart transformer )

\section{Nonlinear loads}

For completeness, also the case with a nonlinear load and complex line parameters is included. The simulation results are depicted in Fig. 21. The $25 \Omega$ load L2 is, in this simulation, changed to a rectifier bridge feeding this load, thus, a nonlinear load. The inductive components of the line parameters have also changed: S1 becomes $1 \Omega$ in series with $5 \mathrm{mH}, \mathrm{S} 3$ is $0.1 \Omega$ in series with $5 \mathrm{mH}$ and $\mathrm{Sq}$ has changed to $5 \mathrm{mH}$.

From the simulation, it follows that despite the combination of: 1) the droop controllers with nonlinear loads and 2) the voltage-based control strategies with complex line components, a stable microgrid operation is obtained. The microgrid with smart transformer shows good results despite the nonlinear loads and the complex line impedances.

\section{CONCLUSION}

In conclusion, by implementing a smart transformer at the PCC, the power exchange between the microgrid and the utility grid can be controlled by altering the microgrid-side voltage of the smart transformer. In this paper, it is also shown that the microgrid elements can use the same control algorithm in the grid-connected mode with smart transformer as in the islanded mode. The reason is that the control strategies of the DG units, active loads and smart transformer are all voltage-based.

From the simulations, it follows that the smart transformer gives more control flexibility to the microgrid. To control the power exchange between microgrid and utility grid, the utility grid only needs to communicate to the smart transformer, instead of to all microgrid elements. The smart transformer aggregates this information with the voltage information of the microgrid to determine its power exchange and all microgrid 


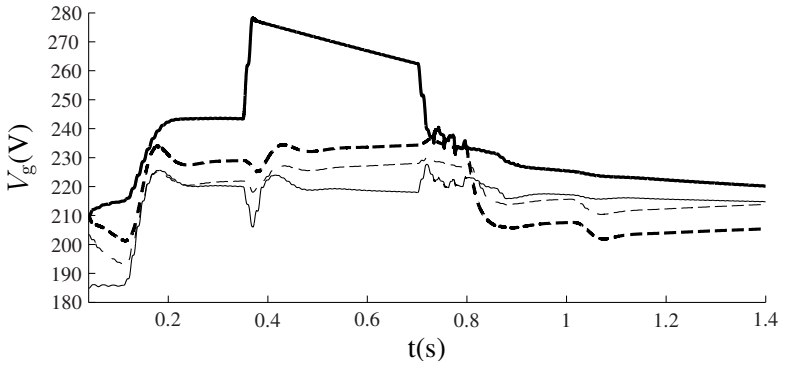

(a) Microgrid voltage

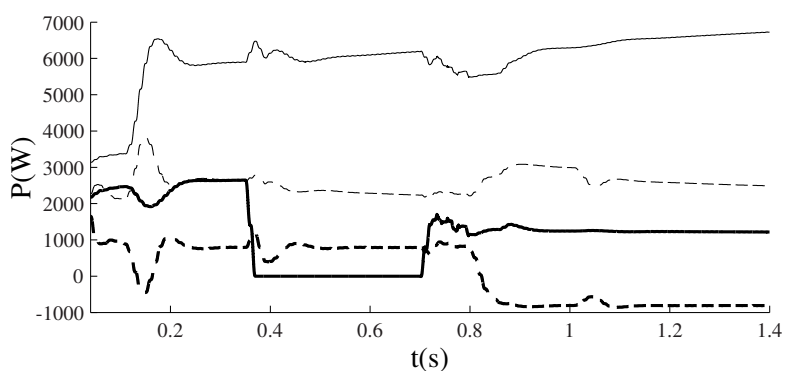

(b) Active power to the electrical network

Fig. 21. Dynamic profile: with smart transformer and nonlinear loads $(-=$ $\mathrm{G} 1 ;----=\mathrm{G} 2 ;-=\mathrm{G} 3,----=$ smart transformer )

elements automatically respond. In this way, the smart transformer enables the microgrid to become a real controllable entity within the electrical network.

\section{ACKNOWLEDGEMENTS}

This work is financially supported by the FWO-Vlaanderen (Research Foundation - Flanders, Belgium). T. Vandoorn thanks the FWO for the Fellowship received. The research was carried out in the frame of the Inter-university Attraction Poles programme IAP-VI-021, funded by the Belgian Government. The work of Jeroen De Kooning is carried out in the frame of the FWO Project G.0587.07N.

\section{REFERENCES}

[1] R. Lasseter, "Microgrids," Proc. Power Eng. Soc. Winter Meeting, pp. 305-308, 2002.

[2] R. H. Lasseter, A. Akhil, C. Marnay, J. Stephens, J. Dagle, R. Guttromson, A. Meliopoulous, R. Yinger, and J. Eto, "The CERTS microgrid concept, white paper on integration of distributed energy resources," in California Energy Commission, Office of Power Technologies - U.S. Department of Energy, LBNL-50829, http://certs.lbl.gov, Apr. 2002.

[3] A. Engler, O. Osika, M. Barnes, N. Jenkins, and A. Arulampalam, DB1 Local Micro Source controller strategies and algorithms. www.microgrids.eu/micro2000, European Commission, Feb. 2004.

[4] H. Jiayi, J. Chuanwen, and X. Rong, "A review on distributed energy resources and microgrid," Renewable and Sustainable Energy Reviews, vol. 12 , no. 9, pp. 2472-2483, Dec. 2008.

[5] C. Marnay and G. Venkataramanan, "Microgrids in the evolving electricity generation and delivery infrastructure," in Proc. IEEE PES General Meeting, Montréal, Canada, June 18-22, 2006.

[6] P. M. Costa and M. A. Matos, "Assessing the contribution of microgrids to the reliability of distribution networks," El. Power Systems Research, vol. 79, no. 2, pp. 382-389, Feb. 2009

[7] P. Basak, A. K. Saha, S. Chowdhury, and S. P. Chowdhury, "Microgrid: control techniques and modelling," in The 44th International Universities' Power Engineering Conference (UPEC 2009). Glasgow, Scotland, Sep. 1-4, 2009.
[8] A. G. Tsikalakis and N. D. Hatziargyriou, "Centralized control for optimizing microgrids operation," IEEE Trans. Energy Convers., vol. 23, no. 1, pp. 241-248, Mar. 2008.

[9] N. Lidula and A. D. Rajapakse, "Microgrids research: A review of experimental microgrids and test systems," Renewable and Sustainable Energy Reviews, vol. 15, no. 1, pp. 186-202, 2011.

[10] H. Farhangi, "The path of the smart grid," in IEEE Power \& Energy Magazine, Jan./Feb. 2010, vol. 8, no. 1, pp. 18-28.

[11] J. C. Vasquez, J. M. Guerrero, J. Miret, M. Castilla, and L. G. De Vicuña, "Hierarchical control of intelligent microgrids," in IEEE Industrial Electronics Magazine, Dec. 2010, vol. 4, no. 4, pp. 23-29.

[12] A. Mehrizi-Sani and R. Iravani, "Potential-function based control of a microgrid in islanded and grid-connected modes," IEEE Trans. Power Syst., vol. 25, no. 4, pp. 1883-1891, Nov. 2010.

[13] N. Hatziargyriou, H. Asano, R. Iravani, and C. Marnay, "Microgrids: an overview of ongoing research, development, and demonstration projects," in IEEE Power \& Energy Magazine, Jul./Aug. 2007, vol. 5, no. 4, pp. 78-97.

[14] B. Kroposki, R. Lasseter, T. Ise, S. Morozumi, S. Papathanassiou, and N. Hatziargyriou, "A look at microgrid technologies and testing projects from around the world: making microgrids work," in IEEE Power \& Energy Magazine, May/June 2008, vol. 6, no. 3, pp. 40-53.

[15] BC Hydro. Distribution power generator islanding guidelines. [Online]. Available: www.bchydro.com, Jun.2006

[16] M. Gauthier, C. Abbey, F. Katiraei, J.-L. Pepin, M. Plamondon, and G. Simard, "Planned islanding as a distribution system operator tool for reliability enhancement," in $19^{\text {th }}$ International Conference on Electricity Distribution, Vienna, May 21-24, 2007.

[17] F. Katiraei, C. Abbey, S. Tang, and M. Gauthier, "Planned islanding on rural feeders - utility perspective," in IEEE PES 2008 General Meeting, Pittsburgh, Pennsylvania, July 20-24, 2008.

[18] European Commission, "European smartgrids technology platform: vision and strategy for Europe's electricity networks in the future," Community Research, Tech. Rep., 2006.

[19] R. H. Lasseter and P. Paigi, "Microgrid: A conceptual solution," in Proc. IEEE Power Electron. Spec. Conf. (PESC 2004), Aachen, Germany, 2004.

[20] A. Engler, O. Osika, M. Barnes, and N. Hatziargyriou, DB2 Evaluation of the local controller strategies. www.microgrids.eu/micro2000, Jan. 2005.

[21] M. Marwali, J.-W. Jung, and A. Keyhani, "Control of distributed generation systems - part II: Load sharing control," IEEE Trans. Power Electron., vol. 19, no. 6, pp. 1551-1561, Nov. 2004.

[22] S. Barsali, M. Ceraolo, P. Pelacchi, and D. Poli, "Control techniques of dispersed generators to improve the continuity of electricity supply," in Proc. IEEE PES Winter Meeting, 2002, pp. 789-794.

[23] F. Katiraei, R. Iravani, N. Hatziargyriou, and A. Dimeas, "Microgrids management: controls and operation aspects of microgrids," Power and Energy Magazine, vol. 6, no. 3, pp. 54-65, May/June 2008.

[24] M. C. Chandorkar, D. M. Divan, and R. Adapa, "Control of paralle connected inverters in standalone ac supply systems," IEEE Trans. Ind. Appl., vol. 29, no. 1, pp. 136-143, Jan./Feb. 1993.

[25] F. A. Bhuiyan and A. Yazdani, "Multimode control of a DFIG-Based wind-power unit for remote applications," IEEE Trans. Power Del., vol. 24, no. 4, pp. 2079-2089, Oct. 2009.

[26] C. Sao and P. Lehn, "Control and power management of converter fed microgrids," IEEE Trans. Power Syst., vol. 23, no. 3, Aug. 2008.

[27] J. M. Carrasco, L. G. Franquello, J. T. Bialasiewicz, E. Galván, R. C. P. Guisado, M. A. M. Prats, J. I. León, and N. Moreno-Alfonso, "Powerelectronic systems for the grid integration of renewable energy sources: A survey," IEEE Trans. Ind. Electron., vol. 53, no. 4, pp. 1002-1016, Aug. 2006.

[28] T. C. Green and M. Prodanovíc, "Control of inverter-based micro-grids," Electric Power Systems Research, vol. 77, no. 9, pp. 1204-1213, July 2007.

[29] T. L. Vandoorn, B. Meersman, L. Degroote, B. Renders, and L. Vandevelde, "A control strategy for islanded microgrids with dc-link voltage control," IEEE Trans. Power Del., vol. 26, no. 2, pp. 703-713, Apr. 2011.

[30] M. Pipattanasomporn, H. Feroze, and S. Rahman, "Multi-agent systems in a distributed smart. grid: Design and implementation," in Power systems conference and exposition (PSCE09). Seattle, Washington, Mar. 2009.

[31] M. Prodanović and T. C. Green, "High-quality power generation through distributed control of a power park microgrid," IEEE Trans. Ind. Electron., vol. 53, no. 5, pp. 1471-1482, Oct. 2006.

[32] N. Pogaku, M. Prodanović, and T. C. Green, "Modeling, analysis and testing of autonomous operation of an inverter-based microgrid," IEEE Trans. Power Electron., vol. 22, no. 2, pp. 613-625, Mar. 2007. 
[33] Y. Li and Y. W. Li, "Power management of inverter interfaced autonomous microgrid based on virtual frequency-voltage frame," IEEE Trans. on Smart Grid, vol. 2, no. 1, pp. 30-40, Mar. 2011.

[34] P. Arboleya, D. Diaz., J. M. Guerrero, P. Garcia, F. Briz, C. Gonzalez Moran, and J. G. Aleisxandre, "An improved control scheme based in droop characteristic for microgrid converters," Electric Power Systems Research, vol. 80, no. 10, pp. 1215 - 1221, Oct. 2010.

[35] F. Gao and M. R. Iravani, "A control strategy for a distributed generation unit in grid-connected and autonomous modes of operation," IEEE Trans. Power Del., vol. 23, no. 2, pp. 850-859, Apr. 2008.

[36] J. M. Guerrero, J. C. Vásquez, J. Matas, L. García de Vicuña, and M. Castilla, "Hierarchical control of droop-controlled AC and DC microgrids - A general approach towards standardization," IEEE Trans. Ind. Electron., vol. 58, no. 1, pp. 158-172, Jan. 2011.

[37] T. L. Vandoorn, B. Renders, L. Degroote, B. Meersman, and L. Vandevelde, "Active load control in islanded microgrids based on the grid voltage," IEEE Trans. on Smart Grid, vol. 2, no. 1, pp. 139-151, Mar. 2011.

[38] H. Laaksonen, P. Saari, and R. Komulainen, "Voltage and frequency control of inverter based weak LV network microgrid," in 2005 International Conference on Future Power Systems, Amsterdam, Nov. 18, 2005.

[39] T. L. Vandoorn, B. Renders, B. Meersman, L. Degroote, and L. Vandevelde, "Reactive power sharing in an islanded microgrid," in 45th International Universities Power Engineering Conference (UPEC 2010), Cardiff, Wales, Aug. 31 - Sep. 3, 2010.

[40] T. Zhou and B. François, "Energy management and power control of a hybrid active wind generator for distributed power generation and gric integration," IEEE Trans. Ind. Electron., vol. 58, no. 1, pp. 95-104, Jan. 2011.

[41] H. Fakham, D. Lu, and B. Francois, "Power control design of a battery charger in a hybrid active PV generator for load-following applications," IEEE Trans. Ind. Electron., vol. 58, no. 1, pp. 85-94, Jan. 2011.

[42] J. M. Guerrero, J. Matas, L. García de Vicuña, M. Castilla, and J. Miret "Decentralized control for parallel operation of distributed generation inverters using resistive output impedance," IEEE Trans. Ind. Electron. vol. 54, no. 2, pp. 994-1004, Apr. 2007.

[43] J. M. Guerrero, J. C. Vásquez, J. Matas, M. Castilla, and L. García de Vicuña, "Control strategy for flexible microgrid based on parallel lineinteractive UPS systems," IEEE Trans. Ind. Electron., vol. 56, no. 3, pp. 726-736, Mar. 2009.

[44] J. Matas, L. G. de Vicuña, and J. C. Vasquez, "Virtual impedance loop for droop-controlled single-phase parallel inverters using a second order general integrator scheme," IEEE Trans. Power Electron., vol. 25, no. 12, p. 2993, Dec. 2010

[45] W. Yao, M. Chen, J. M. Guerrero, and Z.-M. Qian, "Design and analysis of the droop control method for parallel inverters considering the impact of the complex impedance on the power sharing," IEEE Trans. Ind. Electron., vol. 58, no. 2, pp. 576-588, Feb. 2011.

[46] P. Siano, P. Chen, Z. Chen, and A. Piccolo, "Evaluating maximum win energy exploitation in active distribution networks," IET Generation, Transmission \& Distribution, vol. 4, no. 5, pp. 598 - 608, May 2010.

[47] C. Cecati, C. Citro, A. Piccolo, and P. Siano, "Smart operation of wind turbines and diesel generators according to economic criteria," IEEE Trans. Ind. Electron., vol. PP, no. 99 (forthcoming), pp. 1-1, 2011, digital Object Identifier: 10.1109/TIE.2011.2106100

[48] C. Yuen, A. Oudalov, and A. Timbus, "The provision of frequency contro reserves from multiple microgrids," IEEE Trans. Ind. Electron., vol. 58 , no. 1, pp. 173-183, Jan. 2011.

[49] R. Majumder, M. Dewadasa, A. Ghosh, G. Ledwich, and F. Zare, "Contro and protection of a microgrid connected to utility through back-to-back converters," Electr. Power Syst. Res., vol. 81, no. 7, pp. $1424-1435$, 2011

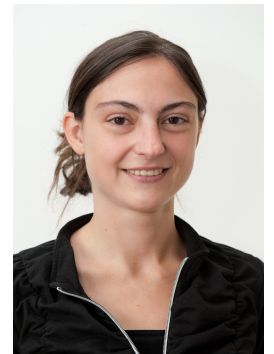

Tine Vandoorn (S'09) was born in Torhout, Belgium in 1985. She received the M.S. in electromechanica engineering from Ghent University, Ghent, Belgium, in 2008. In 2008, she joined the Electrical Energy Laboratory (EELAB) of Ghent University where she is currently pursuing the Ph.D. degree. Her present research interests include electric power systems, voltage and power control of distributed generation units, management of microgrids and smart microgrids. In 2009, she was awarded a grant as Ph.D. fellow of the Research Foundation - Flanders (FWO).

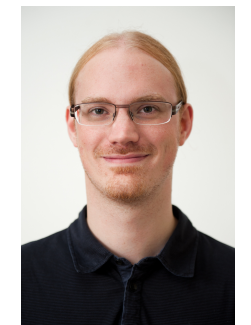

Jeroen De Kooning ( $\mathrm{S}^{\prime} 09$ ) was born in Kapellen, Belgium in 1987. He received the M.S. degree in electromechanical engineering from Ghent University, Belgium, in 2010. Since then, he is with the Electrical Energy Laboratory (EELAB) of Ghent University and is currently pursuing the Ph.D degree. His present research interests include wind energy systems and control of power electronic converters.

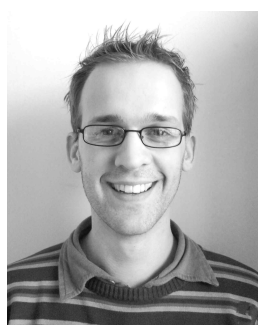

Bart Meersman ( $\left.\mathrm{S}^{\prime} 07\right)$ was born in Sint-Niklaas, Belgium on July 29, 1983. He received the M.S degree in electromechanical engineering from Ghent University, Belgium, in 2006. Since then, he is with the Electrical Energy Laboratory (EELAB) of Ghent University and is currently working towards a Ph.D. degree. His present research interests include dynamic phasors, renewable energy applications, digital control of power electronic converters and their contribution to power quality.

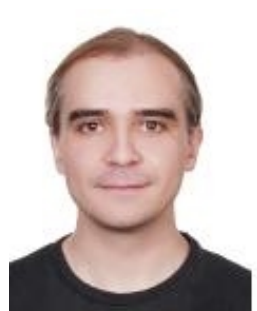

Prof. Josep M. Guerrero (S'01-M'04-SM'08) received the B.S. degree in telecommunications engineering, the M.S. degree in electronics engineering, and the Ph.D. degree in power electronics from the Technical University of Catalonia, Barcelona, Spain, in 1997, 2000 and 2003, respectively. He is an Associate Professor with the Department of Automatic Control Systems and Computer Engineering, Technical University of Catalonia, Barcelona, where he currently teaches courses on digital signal processing, FPGAs, microprocessors, and renewable energy. Since 2004, he has been responsible for the Renewable Energy Laboratory, Escola Industrial de Barcelona. He has been a visiting Professor at Zhejiang University, China, and University of Cergy-Pontoise, France. From 2011 he is a Full Professor at the Department of EnergyTechnology, Aalborg Universiy, Denmark. His research interests include power electronics converters for distributed generation and distributed energy storage systems, control and management of microgrids and islanded minigrids, and photovoltaic and wind power plants control.

Dr. Guerrero is an Associate Editor for the IEEE Trans. on Power Electron. and IEEE Trans. on Ind. Electron. He has been Guest Editor of the IEEE Trans. on Power Electron. Special Issues: Power Electrics for Wind Energy Conversion and Power Electronics for Microgrids; and the IEEE Trans. on Ind. Electron. Special Sections: Uninterruptible Power Supplies (UPS) systems, Renewable Energy Systems, Distributed Generation and Microgrids, and Industrial Applications and Implementation Issues of the Kalman Filter. He currently chairs of Renewable Energy Systems Technical Committee of IEEE IES. He is an elected IEEE IES Adcom member.

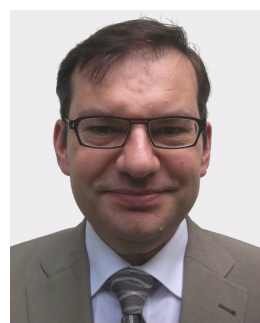

Lieven Vandevelde (M05 - SM07) was born in Eeklo, Belgium, in 1968. He graduated as Master of Electromechanical Engineering and received the $\mathrm{Ph} . \mathrm{D}$ degree from Ghent University, Belgium, in 1992 and 1997, respectively. He is with the Electrical Energy Laboratory (EELAB), Ghent University, where he has been a Professor in electrical power engineering since 2004. His research and teaching activities are in the field of electric power systems, electrical machines and (computational) electromagnetics. 